\title{
Tracking Monetary-Fiscal Interactions across Time and Space*
}

\author{
Michal Franta, ${ }^{\mathrm{a}}$ Jan Libich, ${ }^{\mathrm{b}}$ and Petr Stehlík ${ }^{\mathrm{c}}$ \\ ${ }^{a}$ Czech National Bank \\ ${ }^{\mathrm{b}}$ La Trobe University, CAMA, and VŠB-TU Ostrava \\ ${ }^{\mathrm{c}}$ University of West Bohemia
}

\begin{abstract}
The long-term fiscal outlook of most high-income countries is grim. Should independent central bankers be afraid of an unpleasant monetarist arithmetic, i.e., fiscal imbalances spilling over to monetary policy and jeopardizing price stability? To provide some insights, this paper tracks the interactions between fiscal and monetary policies in the data since 1980 for Australia, Canada, Japan, Switzerland, the United Kingdom, and the United States. In doing so it uses a combination of time-varying parameter vector autoregression with sign, magnitude, and contemporaneous restrictions identification. Unlike conventional approaches, this can capture changes in monetary and fiscal behavior that are gradual and differ across the two policies. Our results show that in the United States the degree of monetary policy accommodation of fiscal shocks (debt-financed government spending) increased gradually between the late 1980 s and the 2008 crisis, i.e., over the whole tenure of Chairman Greenspan. In contrast, it seems to have decreased over this period in the United Kingdom,
\end{abstract}

\footnotetext{
*We would like to thank Tomáš Adam, Jacopo Cimadomo, Adrian Pagan, Nora Traum, and our audiences at the American Economic Association meetings, the Czech National Bank, and the 2017 International Journal of Central Banking Research Conference for useful comments. Special thanks go to the discussant Troy Davig and editor Barbara Rossi for constructive suggestions that have improved the paper substantially. The second author gratefully acknowledges financial support from the European Social Fund (CZ.1.07/2.3.00/20.0296) and the Czech Science Foundation (GA402/10/1046, GACR 13-20613S). The third author gratefully acknowledges financial support from the Czech Science Foundation (GA15-00735S). The usual disclaimer applies. Corresponding author: Jan Libich, La Trobe University, Department of Economics and Finance, Melbourne, 3086, Australia; Tel: (613)94792754; E-mail: j.libich@latrobe.edu.au.
} 
Australia, Switzerland, and Canada. Our benchmark analysis and several robustness checks show that legislating numerical inflation targets may account for some of the country differences, presumably because they may shift the strategic power from fiscal to monetary policy. We conclude by considering the implications of our results for the long-term likelihood of an unpleasant monetarist arithmetic in the six countries.

JEL Codes: E61, C10.

\section{Introduction}

Many countries face substantial fiscal challenges going forward. The expansionary responses to the 2008 global financial crisis combined with a large intertemporal gap between government expenditures and revenues have led to rapidly growing debt-to-GDP ratios, forecast to deteriorate further due to aging populations 1

These cyclical and structural developments have brought a new wave of discussions on whether fiscal policy may affect the conduct of monetary policy and, if so, how. Is formal central bank independence sufficient to shelter monetary policy from long-term fiscal imbalances? Or do these eventually spill over and lead to a suboptimally high level or variability of inflation, as some observers fear? The seminal work of Sargent and Wallace (1981) showed that when fiscal policymakers are unable or unwilling to balance their books, the central bank is subject to an unpleasant monetarist arithmetic. Under such fiscal dominance, undesirable departures from price stability due to forced debt monetization are likely to arise 2

The paper makes two main contributions - one on the macroeconomic policy front and one on the econometric front. Regarding the former, it tracks monetary-fiscal policy interactions over time in six advanced countries in order to provide some insights into the long-term danger of an unpleasant monetarist arithmetic.

\footnotetext{
${ }^{1}$ See, for example, International Monetary Fund (2009), which reports the net present value of the impact of aging-related spending on fiscal deficits to be in the order of hundreds of percent of GDP for most high-income countries.

${ }^{2}$ Leeper's (1991) fiscal theory of the price level (FTPL) provides another avenue through which excessive fiscal policy may threaten monetary stability.
} 
Specifically, we estimate how monetary policy responses to debtfinanced government spending shocks have evolved since 1980 (with a focus on the pre-2008 period) in Australia, Canada, Japan, Switzerland, the United Kingdom, and the United States.

Our main finding is that monetary policy in the United States has become more accommodative of fiscal shocks over time, well before the 2008 crisis. The gradually growing "monetary accommodation" - reducing interest rates in response to debtfinanced government expenditures - can be observed throughout the whole tenure of Chairman Alan Greenspan, i.e., starting in the late 1980s. Furthermore, it occurs not only on impact (the period the shock occurred) but also over longer horizons. This is in contrast to the United Kingdom, Australia, Canada, and Switzerland, where the opposite trend of less accommodation seems to have occurred. In fact, in the latter three countries the central banks started "monetary offsetting," that is, raising interest rates in response to debtfinanced government spending.

Our subsequent analysis provides some (albeit not fully conclusive) evidence that the differences in monetary responses to fiscal shocks observed across countries and over time may be partly due to adoption of numerical inflation targets. It appears that such explicit monetary commitment may be able to discipline the central bank-improving monetary outcomes, as well as the governmentimproving fiscal outcomes. These effects can best be understood through a game of chicken, in which both monetary and fiscal policymakers prefer the other policy to deal with growing long-term debt overhang, but both would like to avoid a fiscal crisis that arises if neither institution does so. In game-theoretic terms, there are two asymmetric pure-strategy Nash equilibriums and one in mixed strategies (representing regime switching). In such a strategic situation, transparent and accounted-for inflation targets shift the power away from the fiscal policymaker to the monetary policymaker, making the central bank the leader in the game. Because of that, legislated numerical inflation targets may reduce the likelihood of an unpleasant monetarist arithmetic.

Combining all our results suggests that the longer-term danger of forced debt monetarization of fiscal imbalances is highest in the United States and Japan, lower in Switzerland and the United Kingdom, and lower still in Australia and Canada. 
The paper's methodological contribution, discussed in detail in the next section, is combining the vector autoregression (VAR) featuring time-varying parameters (TVP) with an identification of fiscal shocks based on a mix of sign, magnitude, and contemporaneous restrictions.

The TVP-VAR framework was introduced in Cogley and Sargent (2005) and Primiceri (2005) 3 Its flexibility enables us to examine medium- to long-term changes in policy behavior over and above the short-run stabilization issues explored in fixed-parameter VARs. Given the dire long-term fiscal projections in most high-income countries, we believe that such extended focus is warranted. In comparison with standard approaches featuring structural breaks, the TVP-VAR framework allows for structural policy changes (i) to be gradual, and (ii) to differ in their timing across the two policies. For these reasons, an analysis based on TVP-VARs may be superior to an analysis based on data subsamples 4 In addition, the employed framework assumes stochastic volatility, which is an important factor to estimate the dynamics accurately. It must, however, be acknowledged that the use of TVP-VARs requires a reduced number of endogenous variables and lags to keep the set of model parameters manageable 5

Kirchner, Cimadomo, and Hauptmeier (2010) and Pereira and Lopes (2010) employed the TVP-VAR framework to assess the effect of fiscal policy shocks. The former paper focuses on the euro area, using the traditional recursive assumption (e.g., as Fatás and

\footnotetext{
${ }^{3}$ TVP-VARs have been used by many studies primarily to analyze the monetary policy transmission (e.g., Canova, Gambetti, and Pappa 2007; Benati and Surico 2008). But there have also been applications to fiscal policy (Kirchner, Cimadomo, and Hauptmeier 2010; Pereira and Lopes 2010), financial issues (Abbate et al. 2016), exchange rate dynamics (Mumtaz and Sunder-Plassmann 2013), oil price shocks transmission (Baumeister and Peersman 2013), yield-curve dynamics (Bianchi, Mumtaz, and Surico 2009) and business cycle dynamics in general (Benati 2008).

${ }^{4}$ It has been documented that in many advanced countries monetary and fiscal policy with their policy regimes have changed over time; see, for example, Clarida, Galí, and Gertler (1998) or Davig and Leeper (2011). Fiscal policy analyses based on subsamples can be found in Blanchard and Perotti (2002), Perotti (2008), or Pappa (2010).

${ }^{5}$ With five endogenous variables and two lags, our analysis already features over 10,000 parameters to estimate.
} 
Mihov 2001) to identify government spending shocks. Pereira and Lopes (2010) examine the United States and identify the tax-netof-transfers shock and the spending shock. This is along the lines of Blanchard and Perotti (2002), who exploit institutional information on taxes and transfers to separate automatic movements of fiscal variables from fiscal policy shocks.

While the identification approach in Kirchner, Cimadomo, and Hauptmeier (2010) and Pereira and Lopes (2010) based on the assumption of lagged reactions among endogenous variables is suitable in many contexts, it may be too restrictive for monetaryfiscal interactions. This is because it implies that either the monetary authority does not react contemporaneously to fiscal shocks or the fiscal authority neglects contemporary movements in monetary policy. In other words, such specification implicitly imposes unrealistic timing assumptions about the interaction between the central bank and the government. As the game-theoretic examination of monetary-fiscal interactions dating back to Sargent and Wallace (1981) suggests, the exact timing of moves determining policy leadership is a crucial determinant of the outcomes of both policies. Similarly, the empirical investigation of Kirsanova and le Roux (2013) demonstrates that "fiscal policy plays an important role in identifying the monetary policy regime."

Our identification strategy based on sign restrictions therefore has an advantage in that no timing assumptions on the monetaryfiscal interaction need to be imposed. On the other hand, sign restrictions are a weak identification approach, as there are multiple structural models that correspond to the estimated reduced-form model and satisfy the signs imposed on the impulse responses (Fry and Pagan 2011). We mitigate this potential problem by adding a set of contemporaneous and magnitude restrictions 6

The changing patterns of monetary policy responses to fiscal shocks detected in the data made us explore whether a specific institutional reform, namely adoption of legislated inflation targets, may explain some of the differences observed across countries and over

\footnotetext{
${ }^{6}$ This follows, e.g., Paustian (2007), who shows that if a sufficient number of identification restrictions is imposed, the sign of an unconstrained response can be identified correctly.
} 
time. Our estimates offer some indirect (but not fully conclusive) evidence for the possible "disciplining" role of explicit inflation targets in both monetary and fiscal policies. This is in the sense of contributing to less-accommodative monetary responses to fiscal shocks, and a subsequent improvement in the longer-term fiscal balance. Intuitively, the government understands that it can no longer buy votes, because a more committed central bank would send voters the bill in the form of higher mortgage rates 7

Keeping the limitations of our analysis in mind, what are the tentative implications of our findings in regards to longer-term monetary policy outcomes? How likely is forced debt monetization once demographic factors intensify fiscal pressures? Our results suggest that the United States and Japan may feature fiscal dominance, roughly interpretable as the "passive monetary, active fiscal" policy regime in Leeper (1991), so their likelihood of experiencing an unpleasant monetarist arithmetic may be rather high in the medium to long term.

In contrast, our benchmark model places Australia and Canada into, or close to, the monetary dominance regime ("active monetary, passive fiscal"), in which an unpleasant monetarist arithmetic is rather unlikely. Our results for Switzerland and the United Kingdom suggest that neither fiscal nor monetary policy dominates the other, in which case a monetary-fiscal policy conflict over growing public debt is likely to arise further down the track. Therefore, an unpleasant monetarist arithmetic cannot be ruled out a priori 8

\footnotetext{
${ }^{7}$ As the world's first inflation-targeting governor, Don Brash (2011a) argued: "[A] major advantage in having the government and central bank formally agree on the inflation target is that it really does mean that the government is forced to take the inflation target into account as it determines its fiscal policy-because it knows that any major change in the stance of fiscal policy must inevitably trigger a response from the monetary authority. And because most governments are constantly suffering from the temptation to run a more stimulatory fiscal policy, knowing that that may provoke a tighter-than-otherwise monetary policy is a most useful constraint." For more discussion, see Brash (2011b) and Libich, Savage, and Walsh (2011).

${ }^{8}$ While many countries have engaged in austerity measures in the aftermath of the 2008 global financial crisis, these generally have taken the form of short-term budget fixes. They have not performed long-term reforms of the pay-as-you-go pension and health-care schemes that are essential in putting fiscal policy on a sustainable path in an aging population.
} 


\section{The Model}

\subsection{Time-Varying Parameter Vector Autoregression}

The reduced-form TVP-VAR follows Cogley and Sargent (2005) and Primiceri (2005):

$$
y_{t}=X_{t} \beta_{t}+A_{t}^{-1} \Sigma_{t} \varepsilon_{t} \quad t=p+1, \ldots, T,
$$

where $y_{t}$ is an $M \times 1$ vector of endogenous variables, $X_{t}=I_{M} \otimes$ $\left(1, y_{t-1}^{\prime}, \ldots, y_{t-p}^{\prime}\right)$ is a Kronecker product of the identity matrix with a constant and lagged vectors of endogenous variables, $p$ denotes the number of lags, and $\varepsilon_{t}$ denotes the vector of iid structural shocks. An $M(M p+1) \times 1$ vector $\beta_{t}$ stacks reduced-form coefficients, the matrix $A_{t}$ is a lower triangular matrix capturing contemporaneous relations,

$$
A_{t}=\left[\begin{array}{cccc}
1 & 0 & \cdots & 0 \\
\alpha_{21, t} & \ddots & \ddots & \vdots \\
\vdots & \ddots & \ddots & 0 \\
\alpha_{M 1, t} & \cdots & \alpha_{M, M-1, t} & 1
\end{array}\right]
$$

and the matrix of standard deviations of structural shocks, $\Sigma_{t}$, is diagonal:

$$
\Sigma_{t}=\left[\begin{array}{cccc}
\sigma_{1, t} & 0 & \cdots & 0 \\
0 & \ddots & \ddots & \vdots \\
\vdots & \ddots & \ddots & 0 \\
0 & \cdots & 0 & \sigma_{M, t}
\end{array}\right]
$$

The TVPs follow random walks and a geometric random walk:

$$
\begin{array}{ll}
\beta_{i, t}=\beta_{i, t-1}+u_{t}^{i} & i=1, \ldots, M^{2} p+M, \\
\alpha_{i, t}=\alpha_{i, t-1}+v_{t}^{i} & i=1, \ldots,\left(M^{2}-M\right) / 2, \\
\log \left(\sigma_{i, t}\right)=\log \left(\sigma_{i, t-1}\right)+w_{t}^{i} & i=1, \ldots, M .
\end{array}
$$

Model innovations are assumed to be jointly normally distributed:

$$
\left[\begin{array}{c}
\varepsilon_{t} \\
u_{t} \\
v_{t} \\
w_{t}
\end{array}\right] \sim N\left(0,\left[\begin{array}{cccc}
I_{M} & 0 & 0 & 0 \\
0 & U & 0 & 0 \\
0 & 0 & V & 0 \\
0 & 0 & 0 & W
\end{array}\right]\right),
$$


where the vectors $u_{t}, v_{t}$, and $w_{t}$ consist of innovations as introduced in (2)-(4). The matrices $U, V$, and $W$ are positive definite. Moreover, $V$ is assumed to be a block diagonal matrix, with blocks constituted by the coefficient innovations from a particular equation, i.e., we assume that innovations to contemporaneous effects are uncorrelated across equations. Finally, we follow Cogley and Sargent (2005) and assume the matrix $W$ to be diagonal. As noted in Kirchner, Cimadomo, and Hauptmeier (2010), the reason is that fiscal TVP-VARs usually consist of more variables than VARs for monetary policy analysis and thus we need to reduce the number of parameters.

The estimation of the system (11)-(5) employs a Gibbs sampler. A sample from the joint posterior distribution of the parameter set is obtained from blocks that provide samples from conditional distributions. Thus, draws from the VAR coefficients $\beta_{i, t}$, contemporaneous relations $\alpha_{i, t}$, volatility states $\sigma_{i, t}$, and the hyperparameters $U, V$, and $W$ are produced by the sampler in turn. A detailed description of the sampler and priors used can be found in appendix 1. The Gibbs sampler generates 20,000 draws after a burn-in period of 20,000. Only every fifth draw is kept to avoid the autocorrelation of draws. Convergence diagnostics are presented in appendix 2 .

\subsection{Endogenous Variables}

Our set $y_{t}$ of endogenous variables consists of five variables: output, private consumption, the short-term interest rate, government debt, and government spending (consumption plus investment). This adds government debt to the four endogenous variables included in the baseline analyses of Kirchner, Cimadomo, and Hauptmeier (2010) and Pereira and Lopes (2010) (the latter paper uses taxes net of transfers instead of private consumption). Such choice is very close to the set of endogenous variables usually employed in VAR studies dealing with fiscal policy issues. VARs for monetary policy analysis use mainly output, the interest rate, inflation, and the exchange rate. It would be our preferred choice to also include the latter two variables in our estimation and thus better capture the monetary policy rule and open-economy features. But it is not 
computationally feasible due to the large number of estimated parameters in the TVP-VAR framework 9

Nevertheless, for robustness we also report results for a specification in which inflation is included (replacing private consumption), and the nature of our baseline findings is unchanged. Furthermore, it must be mentioned that the restricted number of endogenous variables does not necessarily pose a major problem for our analysis due to its specific focus. In the literature (e.g., Mountford and Uhlig 2009) various monetary and price variables are employed to identify the monetary policy shock. These are important, as the interest conventionally lies in the effects of the shock. But our interest lies in strategic monetary-fiscal interactions, so we only need to distinguish between fiscal and monetary policy shocks; we are not primarily interested in the effects of the monetary policy shock. Table 1 will show that even with the short-term interest rate as the only indicator of the monetary policy stance, we are able to distinguish between fiscal, monetary, and business cycle shocks.

\subsection{Identification}

The identification of structural shocks boils down to finding a linear combination of structural shocks $\varepsilon_{t}$ that yields the reduced-form residuals $z_{t}$. The relationship between the two is modeled in (1) as follows:

$$
z_{t}=A_{t}^{-1} \Sigma_{t} \varepsilon_{t} .
$$

Three basic approaches to the identification of fiscal policy shocks have been established in the literature. First, the event-study approach (Ramey and Shapiro 1998) focuses on describing the effects of an unexpected increase in government defense spending. Second, the structural VAR approach (Blanchard and Perotti 2002) draws on the assumption of a lagged reaction of fiscal variables to the changes in economic conditions. Third, the identification scheme based on sign restrictions is employed (Canova and Pappa 2007; Mountford and Uhlig 2009; Pappa 2009), and later enriched by identifying

\footnotetext{
${ }^{9}$ The original Cogley and Sargent (2005) and Primiceri's (2005) TVP-VAR included only three variables, and the vast majority of applications feature four variables.
} 


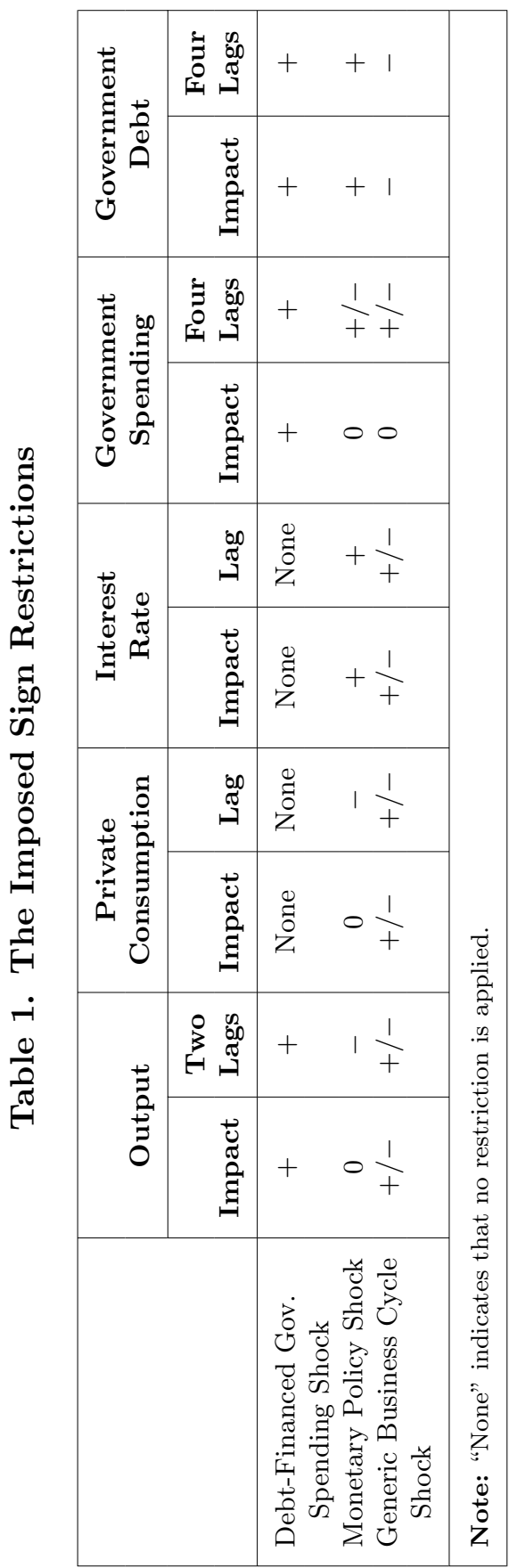


assumptions based on cointegration and magnitude restrictions (e.g., Dungey and Fry 2009).

Our identification procedure complements sign restrictions with magnitude and contemporaneous restrictions, focusing on a government spending shock 10 Government spending is defined as government consumption and investment, i.e., total expenditures excluding government transfers. Similarly to Canova and Pappa (2007), Dungey and Fry (2009), and Pappa (2009), we assume that a positive debt-financed government spending shock increases (i) government spending for four quarters, (ii) government debt for four quarters, and (iii) output for two quarters. As shown in Pappa (2009), such restrictions, at least on impact, are consistent with standard structural models of both the real business cycle and the New Keynesian tradition, and they do not result from productivity, labor supply, or monetary policy shocks, 11

The imposed sign restrictions are described in the first row of table 1 . In the second and third row, table 1 presents reactions of endogenous variables to a monetary policy shock and a generic business cycle shock (e.g., a technology or labor supply shock). An important feature is that the shocks either do not affect government spending contemporaneously or they affect output and government debt in opposite directions.

A rise in output and government debt can, however, also be brought about by a tax cut and/or an increase in transfers. Therefore, to filter out the effects of the government transfer and tax shocks, we impose a magnitude restriction that an identified debtfinanced spending shock does not increase government debt more than the amount of government spending for the four quarters ahead 12 The situation where tax cuts imply an increase of tax

\footnotetext{
${ }^{10}$ Doing so, we avoid assuming passive fiscal policy that would be implied by imposing a tax change corresponding to a spending shock.

${ }^{11}$ Leeper, Walker, and Yang (2010) show, within a neoclassical growth model fit to U.S. post-war data, that implementation delays of government investment can even lead to a slight decline of output in the short run. We discuss anticipation effects of fiscal shocks in appendix 3.

${ }^{12}$ In focusing on monetary-fiscal interactions, we need to distinguish a debtfinanced government spending shock from a tax cut shock and a government transfers shock. This is because the real economy behaves differently after these types of fiscal shocks. For example, private investment is usually crowded out in
} 
revenues cannot be distinguished from the government spending shock within our identification framework, but such a scenario is arguably unlikely. Finally, note that the magnitude restriction plays to some extent a role of an equilibrium condition on the value of real debt that implies that a future increase in spending lowers future primary balances and thus the current value of debt. Leeper and $\mathrm{Li}$ (2015) show how important it is to take into account the intertemporal equilibrium condition for debt valuation, especially in the case of fiscal dominance. Dropping draws of orthonormal matrices that do not satisfy the magnitude restriction essentially means dropping the structural models that violate the condition.

Next, in order to capture the fact that government purchases do not react much to the business cycle, we impose a zero contemporaneous restriction on the effect of a business cycle shock to government spending (see table 1). This is reminiscent of the recursive identification of shocks when government spending is ordered before GDP. Nevertheless, we do not restrict the contemporaneous feedback between government debt and output to allow for the effect of automatic stabilizers on fiscal variables (taxes and debt). The contemporaneous restriction on the relationship between output and government spending enables us to distinguish between fiscal shocks and generic business cycle shocks. So, we basically identify two shocks, which are orthogonal. One follows signs of a debt-financed government spending shock and the other guarantees that there is no contemporaneous reaction of government spending to such shock.

Finally, let us stress that we do not impose any restrictions on the interest rate because it is the variable of our main interestit summarizes the responses of monetary policy to debt-financed spending shocks. Similarly, no restrictions on private consumption are imposed because of the opposite predictions of the traditional Keynesian and real business cycle models. The former predicts an increase whereas the latter predicts a decrease in private consumption following a debt-financed government spending shock (Galí, López-Salido, and Valles 2007).

the case of excessive government spending but not in the case of a tax cut, so the two shocks require a different response from the central bank. 


\subsection{Implementation of the Identification Approach}

Our identification implementation is based on the fact that for any orthonormal matrix $Q$, i.e., for any matrix such that $Q^{\prime} Q=I_{M}$, it holds that

$$
z_{t}=A_{t}^{-1} \Sigma_{t} Q^{\prime} Q \varepsilon_{t}
$$

In such way a new set of uncorrelated structural shocks, $\tilde{\varepsilon}_{t}=Q \varepsilon_{t}$, with the same covariance matrix of reduced-form residuals, is produced 13 To generate orthonormal matrices we use Givens rotations, i.e., orthonormal matrices of the form

$$
Q_{i j}(\theta)=\left(\begin{array}{ccccccc}
1 & \cdots & 0 & \cdots & 0 & \cdots & 0 \\
\vdots & \ddots & \vdots & & \vdots & & \vdots \\
0 & \cdots & \cos (\theta) & \cdots & -\sin (\theta) & \cdots & 0 \\
\vdots & & \vdots & \ddots & \vdots & & \vdots \\
0 & \cdots & \sin (\theta) & \cdots & \cos (\theta) & \cdots & 0 \\
\vdots & & \vdots & & \vdots & \ddots & \vdots \\
0 & \cdots & 0 & \cdots & 0 & \cdots & 1
\end{array}\right)
$$

where the rotation angle is $\theta \in[0, \pi]$. The respective goniometric functions occupy the i-th and $\mathrm{j}$-th columns and the $\mathrm{i}$-th and $\mathrm{j}$-th rows of the matrix. For $5 \times 5$ matrices, any rotation can be constructed as a product of ten possible Givens rotations:

$$
Q(\theta)=\prod_{\substack{i, j=1 \\ i<j}}^{5} Q_{i j}(\theta) .
$$

In order to impose no impact of output on government spending in a given period, we use only nine Givens rotations to guarantee zero at the respective position (the first row and the second column) in the matrix $Q$. Hence we have

$$
\begin{aligned}
Q(\Theta)= & Q_{24}\left(\theta_{1}\right) Q_{23}\left(\theta_{2}\right) Q_{14}\left(\theta_{3}\right) Q_{35}\left(\theta_{4}\right) Q_{34}\left(\theta_{5}\right) Q_{25}\left(\theta_{6}\right) Q_{45}\left(\theta_{7}\right) \\
& Q_{15}\left(\theta_{8}\right) Q_{13}\left(\theta_{9}\right) .
\end{aligned}
$$

\footnotetext{
${ }^{13}$ In contrast to Kirchner, Cimadomo, and Hauptmeier (2010) and Pereira and Lopes (2010), the identification is not an integral part of the estimation procedure. In their case, the estimated matrices of the contemporaneous effects already embed the identification scheme.
} 
For each rotation, the sign and magnitude restrictions are checked. Note that the magnitude restrictions are applied on a particular draw of the rotation matrix, i.e., on a particular structural model. For a given draw of the model parameters, at most forty rotations are tested to find the ones that satisfy the sign and magnitude restrictions. Distributions of impulse responses then arise from the accepted Givens rotations.

Imposing the zero contemporaneous restriction by restricting the set of Givens rotations allows us to avoid the penalty function used, for example, in Mountford and Uhlig (2009). Caldara and Kamps (2010) show how policy conclusions can be affected by the choice of a specific penalty function. Moreover, some papers implement the combination of zero and sign restrictions by rotating only a part of the matrix of contemporaneous effects (e.g., Eickmeier and Hofmann 2013); their structural shocks are no longer orthogonal.

\section{Data}

All variables except the interest rate are in logs of real per capita terms; the sources are described in appendix 6 . The data are quarterly except for government debt, which is yearly, and which we disaggregated into quarters using a simple univariate interpolation method (Boot-Fiebes-Lisman) 14 The data enter our analysis in levels like in Kirchner, Cimadomo, and Hauptmeier (2010) - but unlike in Pereira and Lopes (2010), who detrend the data. We use levels for two reasons. First, trends can reveal valuable information about monetary-fiscal interactions and how these have changed over time. Second, we avoid the possibility of incorrectly imposing cointegration relationships; see Sims, Stock, and Watson (1990).

Our choice of the lag length, namely two, is driven by both the large number of estimated parameters and an attempt to best capture the dynamics of endogenous variables 15 We estimate the model

\footnotetext{
${ }^{14}$ This interpolation is one of the reasons for imposing sign restrictions on the response of debt to four quarters: a change in government debt that occurs anytime during the year is reflected by the debt data in all four quarters. This is also true for the magnitude restrictions.

${ }^{15}$ In our setup two lags imply more than 10,000 parameters to estimate, whereas three lags imply almost 20,000. The exact determination of the lag length based
} 
for Australia, Canada, Japan, Switzerland, the United Kingdom, and the United States. The country choice is driven by our interest in comparing institutional setups with and without a legislated inflation target. As there are only three advanced economies in the latter category (Japan, the United States, and partly Switzerland), we pick an equal number of early inflation targeters. Their choice follows the justification of Dotsey (2006), most importantly the fact that "their inflation rates were fairly well-contained before they adopted inflation targeting."

The data set in our baseline analysis covers the 1980:Q1-2008:Q2 period (for the United Kingdom it begins in 1981:Q1). Our baseline model does not include data from the post-GFC period for four reasons. First, our focus is on strategic monetary-fiscal interactions of the medium- to long-term nature, i.e., cycle-free type behavior, which is why excluding the biggest cyclical deviation in almost a century seems desirable. Second, it is well documented that the post2008 period has featured increased risk, which could bias our conclusions regarding monetary-fiscal interactions (see, e.g., Martin and Milas 2010). Third, during the global financial crisis central banks affected the economy through many channels, including direct subsidies to commercial banks and quantitative easing after hitting the zero lower bound. Mixing periods of conventional and unconventional monetary policy is very problematic; there is no consensus on how to identify monetary and fiscal shocks without a considerable enlargement of the set of variables, which we explained was not feasible. Fourth, our priors are based on ordinary least squares (OLS) estimates of the model on the whole sample, so extreme observations can alter the estimates in a way unrepresentative of the medium- to long-term developments 16

Nevertheless, as a demonstration we report the estimates including post-2008 data for Canada and the United States in section 6.1. This extension shows that while our baseline results are robust,

on the marginal likelihood is beyond the scope of this paper, but its working paper version provides some guidance from the sample autocorrelations.

${ }^{16}$ Even with a broadened set of variables, identification of unconventional monetary policy measures has been subject to a heated debate in the literature, with no consensus emerging yet. Regarding extreme observations, Canova (2007) suggested that in the case of short samples it is preferable not to use a training sample that gets discarded. 
including the recent crisis may overshadow them in magnitude and may therefore lead to a loss of insight.

Two points in relation to our data choices are worth emphasizing. First, to analyze monetary-fiscal interactions, an appropriate short-term interest rate must be chosen that reflects the monetary policy stance for the whole period. This means that we cannot use the currently announced instrument of the central bank, as it is not informative of monetary policy behavior under older-style money growth targeting - performed at the start of our sample. For this reason we mainly use the Treasury bill rate. Second, government spending data are usually available for a general level of government (except the United Kingdom), whereas government debt data are related to central government only. Assuming that the change in general government debt is no smaller than the change in central government debt, the magnitude restrictions imposed imply that the change in general government spending does not exceed the change in general government debt.

\section{Tracking Monetary Responses to Fiscal Shocks}

Our interest in the likelihood of an unpleasant monetarist arithmetic - fiscal dominance over monetary policy-drives our empirical analysis. We estimate impulse response functions (IRFs) of endogenous variables to a positive debt-financed government spending shock. As shown by Fry and Pagan (2011), sign restrictions can recover correct impulse responses to an unknown one-standarddeviation shock, i.e., one cannot distinguish between the shock itself and the contemporaneous effect of the shock on a variable 17 This implies that the signs of the IRF provide accurate information. It should be acknowledged that the same cannot be said with certainty about the magnitudes of the IRFs that are of interest for the comparison between periods. However, assuming that the variance in impacts is driven mainly by the shocks' size - which is essentially imposed by our prior belief on the hyperparameters driving

\footnotetext{
${ }^{17}$ Primiceri (2005) avoids this problem by assuming recursive identification and by estimating the matrix of standard deviations $\Sigma_{t}$ and the matrix of contemporaneous effects $A_{t}$ separately. We adjust the matrices with the rotations and hence forgo the possibility of distinguishing them.
} 
changes in respective parameters (shocks versus contemporaneous effects) - we can also make tentative conclusions about the changes in magnitude.

The impulse responses are normalized with respect to the median impact of the shock on government spending. The size of the impact equals unity, i.e., we discuss the responses of endogenous variables after an unexpected 1 percent increase in real per capita government spending. IRFs are in percent deviations from the steady state. The only exception is the interest rate, which is considered in percentage points.

\subsection{Estimated Impulse Response Functions}

To maintain attention on monetary-fiscal interactions, the main text only reports the IRFs of the interest rate to a debt-financed spending shock 18 Of greatest importance in regards to strategic monetaryfiscal interactions is the central bank's immediate response to the government's actions (i.e., the IRFs on impact), but its responses in the several subsequent quarters may also offer valuable information.

The left column of figure 1 reports the medians of the posterior distributions of IRFs for the horizon of up to sixteen quarters 19 In general, a different IRF is estimated for each quarter in our sample. The right column of figure 1 provides a more detailed picture of the interest rate responses to fiscal shocks on impact and in the third quarter.

\subsection{Empirical Findings}

Eyeballing figure 1, a tentative conclusion is that the degree of monetary accommodation of debt-financed spending shocks seems to have increased in the United States. In contrast, in the remaining

\footnotetext{
${ }^{18}$ For an illustration of the rest of the results, the responses on impact and in the third quarter are available in appendix 4 for all variables and countries.

${ }^{19}$ Using median IRFs represents an approach that is standard in the literature. However, Fry and Pagan (2011) criticize the use of pointwise median impulse response on the grounds of consisting of different rotation matrices, i.e., no single admissible model underlies the whole median response, and they suggest to report the closest-to-median responses. Canova and Paustian (2011) examine this suggestion and conclude that it may not lead to more accurate results. We therefore stick to reporting the medians of the IRF distributions.
} 
Figure 1. IRFs of the Short-Term Interest Rate to a 1 Percent Debt-Financed Government Spending Shock

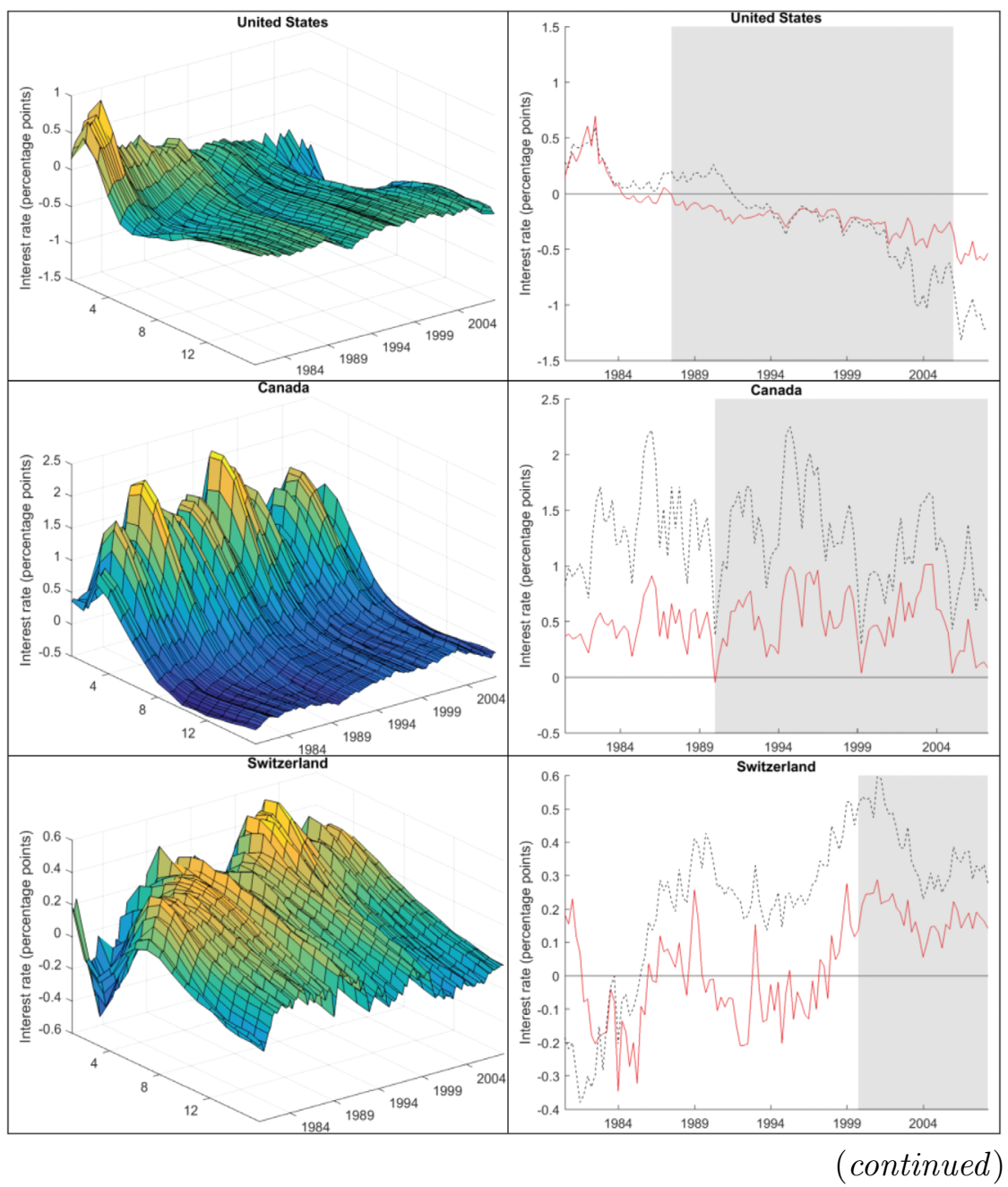




\section{Figure 1. (Continued)}

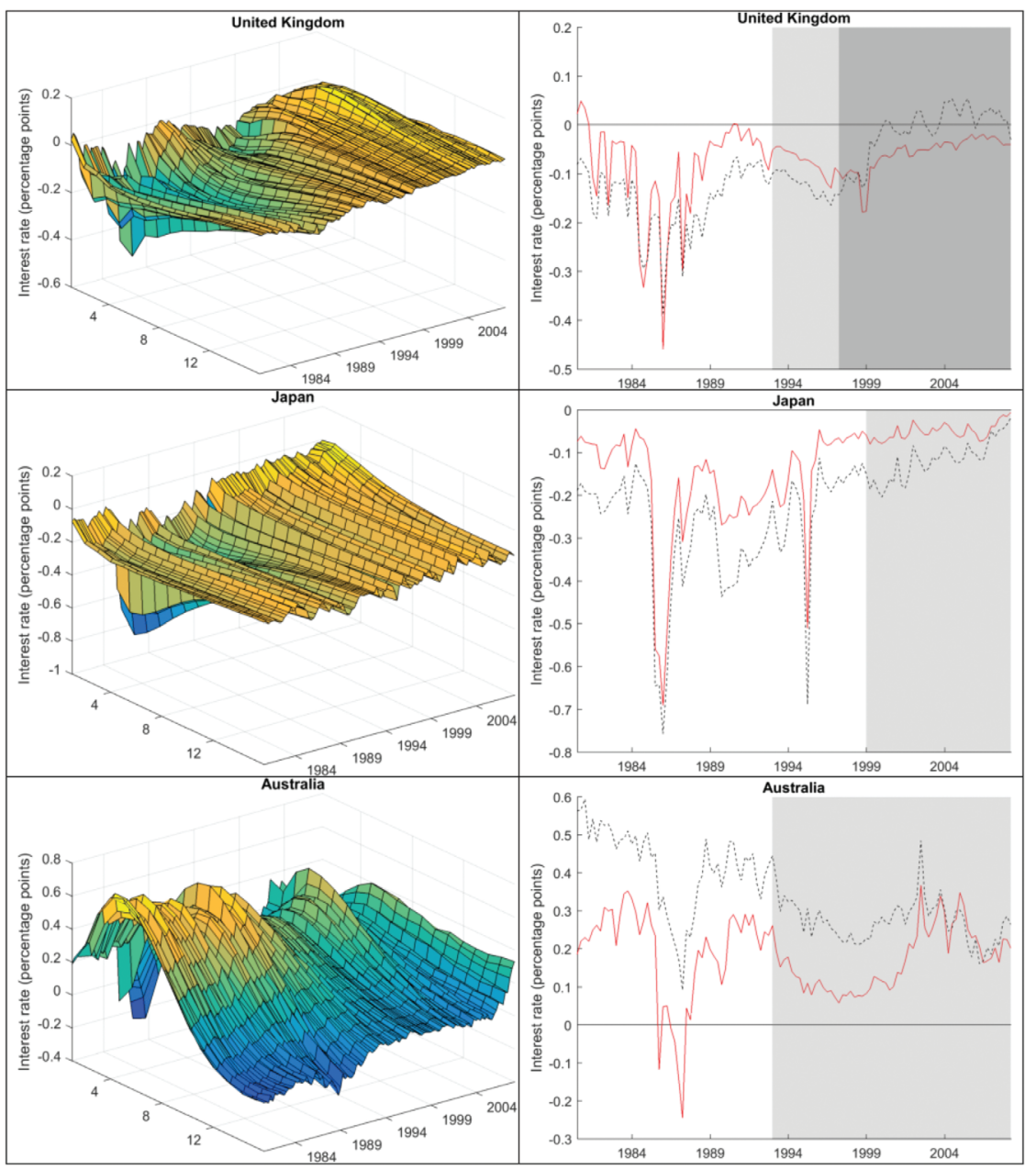

Notes: The left column shows all horizons; the right column shows responses on impact (solid line) and in the third quarter (dotted line). The shaded areas indicate the following: (i) Australia, Canada, and the United Kingdom: introduction of explicit inflation targets (in the latter also the subsequent granting of independence), (ii) Japan: the zero-lower bound period, (iii) United States: change of the Federal Reserve Chairman. 
countries it seems to have decreased or central bank responses to fiscal shocks remained qualitatively unchanged. Let us discuss the observations for each country, taking advantage of the fact that our TVP-VAR framework allows for a nuanced view of the evolution of monetary-fiscal interactions. A further discussion will follow in relation to explicit inflation targets (section 5), various robustness checks (section 6), and the likelihood of an unpleasant monetarist arithmetic (section 7).

The results for the United States are especially noteworthy. A strong monetary offset of fiscal shocks in the early 1980s is apparent in figure 1, reflecting the tug-of-war between Chairman Paul Volcker's disinflation efforts and debt-accumulating fiscal policies of the Reagan government. Such finding is in line with the estimates of Davig and Leeper (2011). They identify this period as the "active fiscal, active monetary" regime in which the government's intertemporal budget constraint is not satisfied and public debt is on an explosive path.

Importantly, figure 1 shows a regime change in U.S. monetary policy. From the late 1980s (around the time of Volcker's replacement by Alan Greenspan) the Federal Reserve (the Fed) started accommodating debt-financed government spending. Furthermore, the degree of monetary accommodation increased gradually over the course of Greenspan's tenure - both on impact and over longer horizons. The degree of accommodation reached its pre-2008 peak during the George W. Bush administration. These findings are in line with Davig and Leeper (2011), whose estimates characterize the period from the early 2000s as "passive monetary" policy accommodating "active fiscal" policy 20 But because our approach can capture gradual changes, it shows that U.S. monetary accommodation of fiscal shocks in fact goes further back in time.

The results for the other countries are in stark contrast to the United States. In terms of Canada, figure 1 shows that the Bank of Canada had a non-accommodative stance throughout the whole sample period. In fact, it tended to offset fiscal shocks - on impact as

\footnotetext{
${ }^{20}$ They are also consistent with Batini, Callegari, and Guerreiro (2011), who provide an estimate of the U.S. "fiscal gap" (unfunded liabilities). They argue that "a full elimination of the fiscal and generational imbalances would require all taxes to go up and all transfers to be cut immediately and permanently by 35 percent" (italics in the original).
} 
well as three to four quarters after the shock. In regards to Switzerland, monetary accommodation on impact was apparent in the 1980s and partly also in the 1990s, but it disappeared in the 2000s. From around 1999 we can see monetary offsetting of fiscal shocks on impact. In terms of the United Kingdom, figure 1 makes apparent that the degree of monetary accommodation of fiscal shocks by the Bank of England decreased over time. The strong monetary accommodation observed in the 1980s was greatly reduced in the early 1990s and largely disappeared in the 2000s.

In the case of Japan, we see monetary accommodation over all horizons throughout the whole sample. Naturally, its magnitude decreased slightly from the mid-1990s because it was constrained by the zero lower bound on interest rates. This is reflected in our results even though we have not explicitly accounted for this bound.

In regards to Australia, figure 1 shows that in the mid-1980s the Reserve Bank of Australia accommodated fiscal shocks on impact, but over the three-to-four-quarter horizon it would reverse this accommodation by tightening monetary policy. Such reactive (backward-looking) rather than proactive (forward-looking) responses tended to lead to a greater volatility in the economy and were therefore inconsistent with the notion of interest rate smoothing and optimal monetary policy in general. Nevertheless, figure 1 shows that in the late 1980s the Bank started offsetting fiscal shocks, and did so even more strongly since the second half of the 1990s, both on impact and over longer horizons.

\section{Exploring the Effect of Explicit Inflation Targets}

Having reported our results regarding the changes in monetary-fiscal interactions over time and across countries, let us now explore one possible explanation for the observed differences. It relates to the institutional design of monetary policy, namely legislating numerical inflation targets. Such explicit targets could in principle serve as the central bank's commitment device and hence alter the strategic balance of power between monetary and fiscal policy.

\subsection{Effect of Policy Leadership}

The seminal work of Sargent and Wallace (1981) highlighted the important effect of policy leadership on monetary-fiscal outcomes. 
It assumed that monetary policy moves upon observing the fiscal actions, so it essentially put the government in the Stackelberg leadership role in the game of chicken against the central bank. The analysis demonstrated that in such a case we are likely to observe fiscal dominance over monetary policy. Intuitively, an unsustainable long-term fiscal stance may strategically force the follower, the central bank, to address fiscal imbalances through monetary tools even if it is formally independent from the government. Such unpleasant monetarist arithmetic, however, jeopardizes price stability, as it breaches the Tinbergen principle. The same conclusion is implied by the "active fiscal, passive monetary" policy regime of Leeper's (1991) fiscal theory of the price level framework.

Importantly, in both frameworks socially undesirable departures from price stability can be avoided under monetary leadership, because the central bank has the stronger hand and can indirectly induce the government to deal with fiscal imbalances. The gametheoretic work in Libich, Nguyen, and Stehlík (2015) provides further insights into such strategic policy interactions by generalizing the discrete Stackelberg leadership concept into a continuous stochastic leadership. The analysis shows that the likelihood of an unpleasant monetarist arithmetic increases in the ratio of fiscal-to-monetary leadership. This ratio determines whether it is the government or the central bank that imposes itself as the stochastic leader in the game of chicken, and to what extent they can induce the other institution to cooperate.

To link these theoretic predictions to the real world, Libich, Nguyen, and Stehlík (2015) use twelve existing measures in the literature to quantify indexes of monetary and fiscal leadership for twenty-five high-income countries. The fiscal leadership index is an average of eight components based on various existing measures of fiscal space, fiscal path, fiscal governance, and fiscal balances, all of which relate to the size of current and future fiscal imbalances. A greater fiscal gap makes a fiscal reform more difficult politically and hence gives the government a first-mover advantage. The monetary leadership index has four components based on the central bank's political transparency and accountability, both of which are increased by legislating an inflation target. This is because such commitment gives the central bank a stronger mandate to offset the possible inflationary effects of excessive fiscal policy by raising 


\section{Figure 2. Monetary vs. Fiscal Leadership Indexes Using Subset of Data from Libich, Nguyen, and Stehlík (2015)}

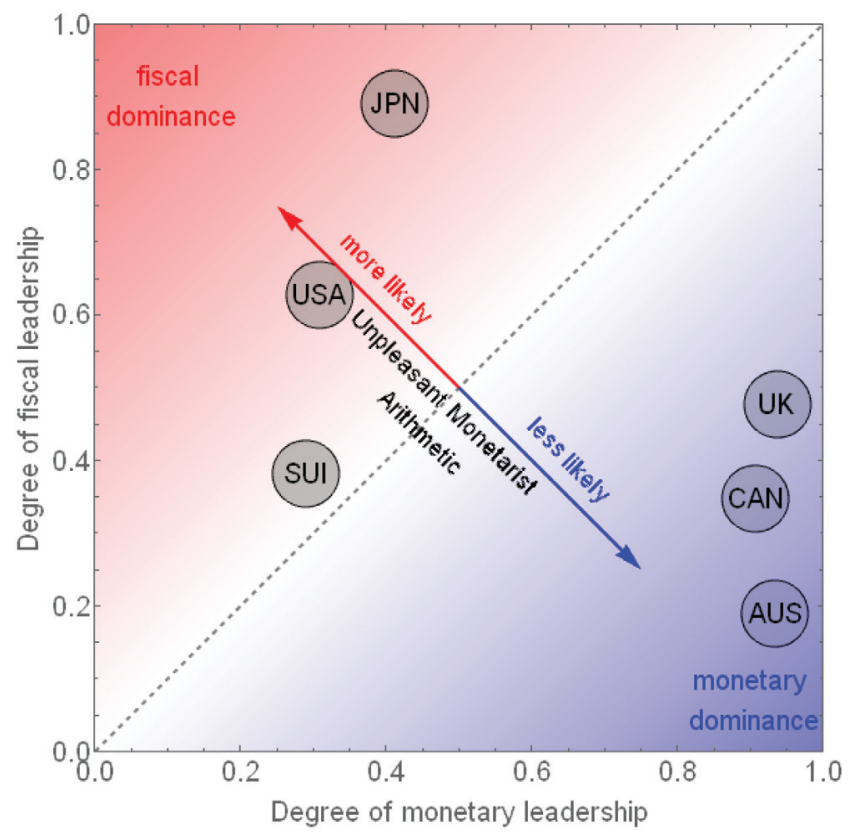

Note: The arrows indicate the likelihood of an unpleasant monetarist arithmetic.

interest rates, i.e., effectively punishing the government by electorally unpopular increases in mortgage rates. The values for the subsample of our six countries are depicted in figure 2 .

The probability of an unpleasant monetarist arithmetic is the highest in the top-left fiscal-dominance corner (with the United States and Japan being the closest), lower in the middle region (Switzerland and the United Kingdom), and the lowest in the bottom-right monetary-dominance corner (Australia and Canada). Given that these findings are consistent with our estimates reported in section 4 , we will consider the following two conjectures.

Conjecture 1. A legislated long-term inflation target may discipline monetary policy. By increasing the central bank's payoff from price stability, it may incentivize monetary policy to stop 
accommodating (or even to start offsetting) excessive debt-financed government spending.

Conjecture 2. A legislated long-term inflation target may discipline fiscal policy. By reducing the government's payoff from excessive debt-financed spending (through conjecture 1) it may improve the long-term fiscal position.

Conjecture 1 is in line with conventional wisdom (see, e.g., Herrendorf 1998), but empirical evidence is scarce. Conjecture 2 is novel and has not yet been examined empirically in the literature. Before exploring the conjectures, however, let us mention one point upfront. The literature has found it challenging to obtain persuasive empirical evidence of monetary and fiscal policy regime shifts. Therefore, being able to attribute our empirical findings to one specific change in the institutional design of monetary policy in a convincing manner (from a statistical point of view) seems very unlikely a priori.

\subsection{Conjecture 1: Can Explicit Inflation Targets Discipline Monetary Policy?}

If conjecture 1 is correct, upon legislating a numerical inflation target, the degree of monetary accommodation of fiscal shocks should decrease or even be reversed into offsetting such shocks by raising interest rates. Conversely, conjecture 1 predicts no change in countries without a legislated inflation objective, or possibly an increase in monetary accommodation due to the (demographics driven) deterioration in many countries' long-term fiscal position.

In order to better contrast monetary policy behavior before and after the introduction of an explicit numerical inflation target, figure 3 reports an additional perspective to figure 1, namely the average responses of the interest rate for the two subperiods. The three explicit inflation targeters (Australia, United Kingdom, Canada) are in the right column, whereas the left column features the two non-targeters (United States, Japan) and Switzerland, the institutional setup of which is somewhere in between the two groups 21

\footnotetext{
${ }^{21}$ For the non-targeting countries, the switch period for the computation of average responses is set to 1992:Q4/1993:Q1 following Dotsey (2006).
} 
Figure 3. Median IRFs of the Interest Rate over a Horizon of Sixteen Quarters in the Two Subsamples

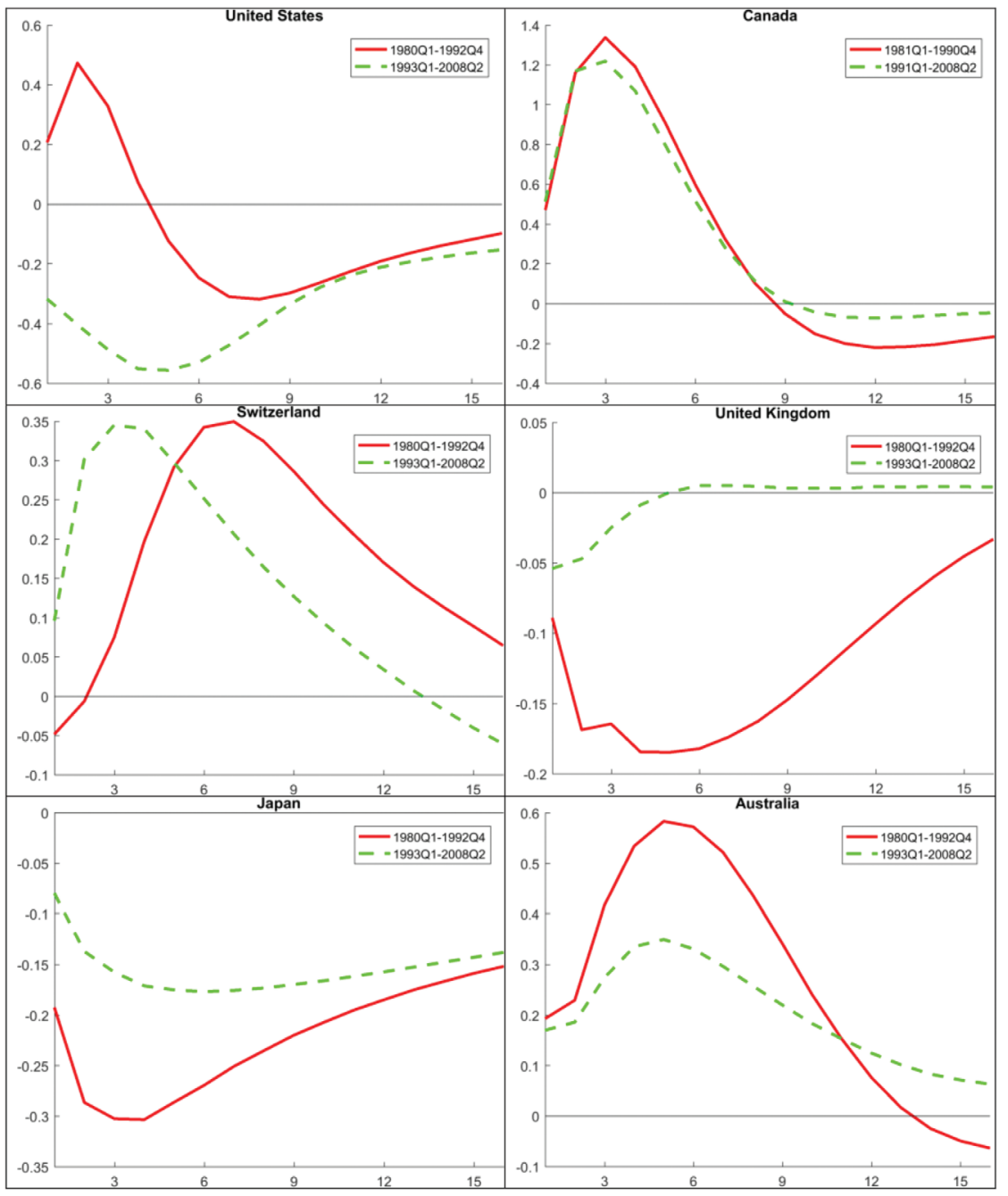

Let us first discuss the results reported in figures 1 and 3 taken at face value, without a reference to a measure of statistical significance. It will become apparent in the next section, in which we report credible (Bayesian confidence) intervals, that any conclusions 
must be drawn with a high degree of caution. The results are only indicative, not conclusive.

In summary, the estimates in figure 3 for all countries are in the direction predicted by conjecture 1. There was less monetary accommodation or more monetary offsetting in Australia, Canada, and the United Kingdom post-adoption of explicit inflation targets, and more accommodation in the United States. The results for Japan and Switzerland are also reconcilable with conjecture 1, as we explain below.

Starting with the targeters, in Canada monetary accommodation of fiscal shocks on impact was not conducted anytime throughout the whole sample. In the three-to-four-quarter horizon, offsetting of these shocks is apparent in figure 1, and its magnitude increased especially from around the 1995-98 period, which was the horizon of the second inflation target announced in 1993. Therefore, while there is no major regime change visible in figures 1 and 3, the results for Canada are broadly consistent with conjecture 1.

Australia's results in figures 1 and 3 show a stronger offset of debt-financed spending post-adoption of a numerical inflation target in 1993. This is, in line with conjecture 1, true of both impact and longer horizons. Since then, the Reserve Bank of Australia has been responding to fiscal shocks by raising the cash rate immediately and by further increasing it for another four quarters to offset the effect of such shocks 22

In terms of the United Kingdom, monetary policy accommodation of fiscal shocks decreased slightly upon the introduction of an explicit inflation target in 1992. But it subsequently increased again and only started decreasing more substantially in the late 1990safter the Bank of England was granted formal independence from the government 23 In line with conjecture 1, post-independence monetary accommodation was markedly lower on impact and non-existent over the medium- to long-term horizon whereby a monetary offset occurred.

\footnotetext{
${ }^{22}$ For example, the Bank famously raised interest rates in November 2007, just two weeks before a federal government election at a time when the Fed was already loosening its stance due to the housing market problems.

${ }^{23}$ This seems to confirm what many have argued: formal instrument independence of the central bank is a prerequisite for the inflation-targeting regime to function effectively (see, e.g., Masson, Savastano, and Sharma 1997).
} 
Let us now turn to the remaining countries that do not have a full-fledged legislated inflation target. The case of the United States was discussed in detail in section 4 , with monetary accommodation of fiscal shocks gradually increasing over all horizons between the late 1980 s and the global financial crisis. The results are thus in line with conjecture 1 . The same can be said about Japan, despite a slight reduction in monetary accommodation from the mid-1990s. This is because Japanese monetary policy remained in the accommodative territory, and the reduction was due to the Bank of Japan hitting the zero lower bound on interest rates, i.e., due to logistic constraints rather than policy preferences.

In regards to Switzerland, the Swiss National Bank is institutionally somewhere in between the above two sets of countries. While not considered a full-fledged inflation targeter, it has an upper bound on medium-term inflation, similar to that of the European Central Bank. Figures 1 and 3 show that in the period from 1999, when the Swiss National Bank reiterated price stability to be an important part of its monetary policy framework, it stopped accommodating fiscal shocks on impact. This is, like the results for all the other five countries, broadly consistent with conjecture 1 .

\subsection{Credible (Bayesian Confidence) Intervals}

To get a sense of the uncertainty regarding our conjecture 1 results, figure 4 presents the median of the posterior distribution of the difference between the short-term interest rate responses after a debtfinanced shock in each subsample. The median difference is supplemented with credible intervals of centered 68 percent of the posterior distribution. The credible intervals for the United States and United Kingdom are plotted, as they represent the typical outcome.

The credible intervals offer some evidence for the Fed's growing accommodation of fiscal shocks in the shorter term. In particular, in the horizon of two quarters, slightly more than 70 percent of the posterior distribution of differences of interest rate responses lie in the positive region. On the other hand, in the United Kingdom for the horizon from six to ten quarters, around 70 percent of the posterior distribution covers negative values, which indicates a move from monetary accommodation to monetary offsetting. For the methodological reasons discussed above, the lack of more conclusive 
Figure 4. Posterior Distribution of the Difference of Interest Rate IRFs in the Two Subsamples for a Horizon of Sixteen Quarters: United States (left) and United Kingdom (right)

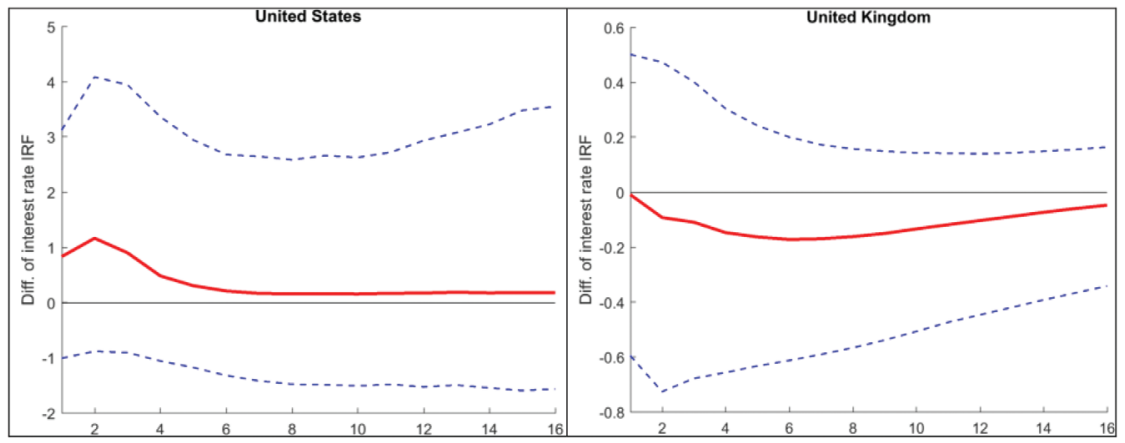

statistical significance is to be expected in this sort of analysis. A further illustration of uncertainty related directly to IRFs can be found in appendix 5 .

\subsection{Conjecture 2: Can Explicit Inflation Targets Discipline Fiscal Policy?}

Conjecture 2 posits that a legislated monetary commitment may, through altered monetary responses to fiscal shocks, improve the government's incentives and thus fiscal outcomes towards sustainability. Two pieces of indirect evidence are presented in Libich, Nguyen, and Stehlík (2015). The first one shows that the correlation between monetary and fiscal leadership is -0.51 among the countries with an independent monetary policy. The second piece is shown, in a somewhat modified fashion, in figure 5. It plots the central government debt-to-GDP ratio for five early inflation targeters and our three non-targeters. To better see the trends, the series are demeaned.

In all five early targeters, one can observe a decrease in government debt starting about one to three years after the formal adoption of an explicit inflation target (in the case of the United Kingdom, after the subsequent granting of central bank instrument independence). In contrast, similar sustained improvements in the 


\section{Figure 5. Central Government Debt to GDP (demeaned) for Five Early Explicit Inflation Targeters (gray lines) and for Our Three Non-targeters (black lines)}

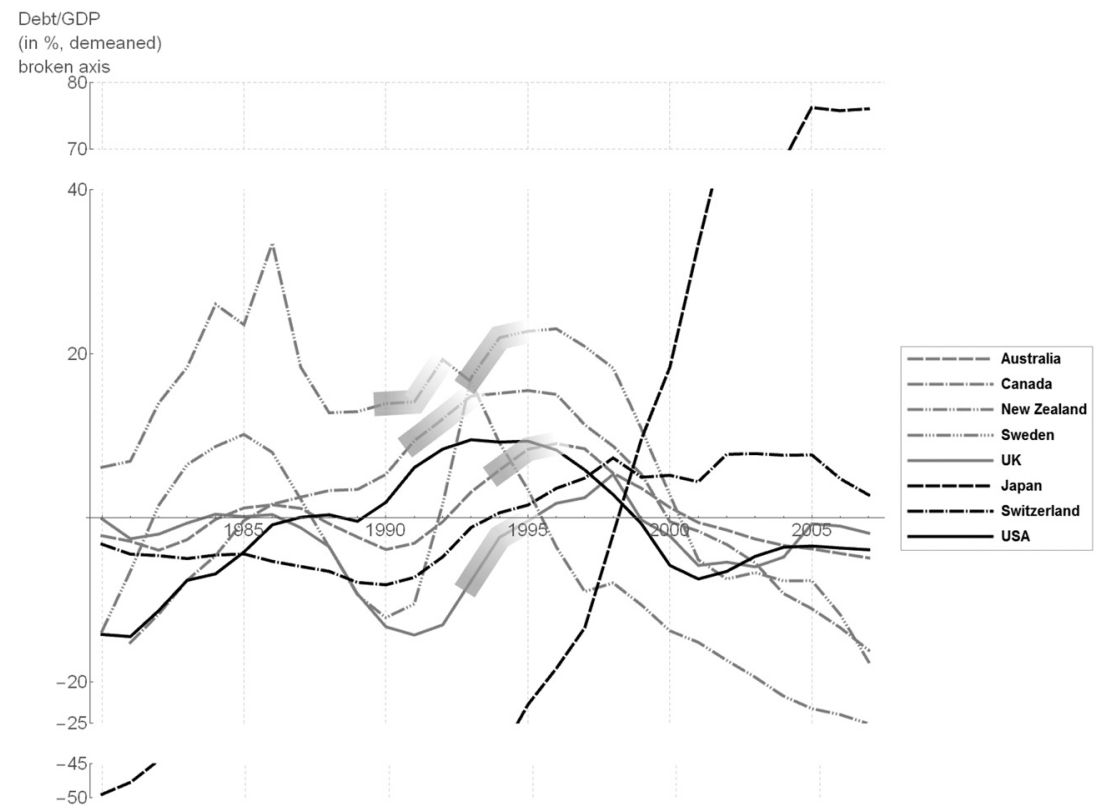

Note: Shaded regions of gray lines indicate the regime's adoption.

long-term fiscal balance are not present for the non-targeters. These findings are robust; the same picture emerges if we plot the (primary) deficit-to-GDP ratio.

It should, however, be emphasized that this finding, as well as the negative correlation of monetary and fiscal leadership, does not constitute evidence of causality. It is plausible that both the introduction of inflation targeting and the improvement of fiscal policy were driven by a common factor. Narrative evidence shows this to be the case for Canada, where fiscal sustainability became the number one policy issue for the public in the late 1980s; see Mauro (2011). But experience of the other countries tells a different story; for an example of New Zealand's account by the world's first inflationtargeting governor, see Brash (2011a, 2011b). He argues: "I have 
not the slightest doubt that having legislation which requires government and central bank to formally agree, and disclose to the public, the inflation rate which the central bank must target has a most useful role in creating strong incentives for good fiscal policy."

The fact that the improvement in fiscal balance was not concurrent with the adoption of inflation targets but was delayed a few years points to a possible causal effect. Furthermore, the observation that fiscal outcomes continued to be well behaved in the inflation-targeting countries depicted in figure 5-long after the original governments departed from the office - provides some anecdotal evidence for the "disciplining effect" of an explicit monetary commitment over fiscal policy. In line with conjecture 2 , reductions in public debt-to-GDP ratios of the early inflation targeters spanned over several subsequent governments of both left- and right-leaning persuasions, and lasted all the way until the 2008 crisis.

Let us consider an alternative perspective on conjecture 2 . It implies that the estimated standard deviations of debt-financed government spending shocks should decrease after a numerical inflation target is legislated. The fact that government spending does not react contemporaneously to the business cycle shocks in our identification approach is an advantage, as it means that the reduced-form residuals in the equation for government spending do not capture immediate reactions of government spending to the state of the macroeconomy. Figure 6 shows the standard deviation of reducedform residuals for government spending - the horizontal line indicating an average of the standard deviations for the two subsamples.

The figure shows - in line with conjecture 2 - that the standard deviation decreased post-adoption of formal inflation targeting in all three considered targeters. Nevertheless, reductions in the volatility of spending are present for the non-targeters as well, so no clear-cut conclusions regarding conjecture 2 can be drawn from this exercise 24

\footnotetext{
${ }^{24}$ This is also because the reduced-form residuals can represent both an unexpected fiscal shock and an immediate reaction to an unexpected monetary policy shock. Therefore, a decrease in the standard deviation of the reduced-form residuals could be caused not only by a reduction in the frequency/size of debt-financed government spending shocks but also by a reduction in the response of the fiscal authority to monetary policy actions.
} 
Figure 6. Estimated Standard Deviations of the Reduced-Form Residuals for Government Spending

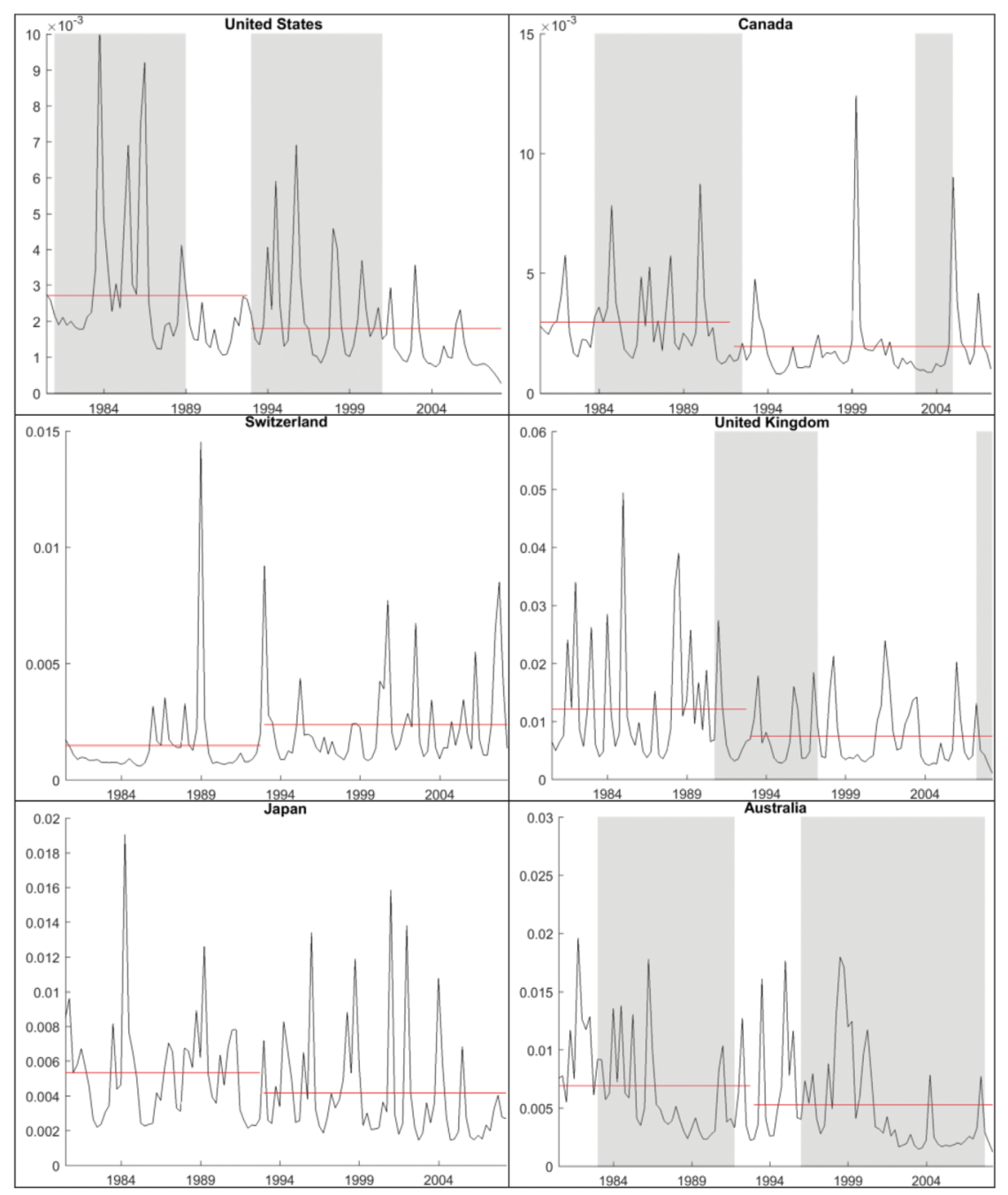

Notes: The vertical lines present the median; the horizontal lines (red in the online version) show the median of average standard deviation over each subsample. For the United States, Canada, the United Kingdom, and Australia, the shaded areas indicate changes in governments. 


\section{Figure 7. IRFs for Canada Estimated on a Longer Sample} (1981:Q1-2016:Q2)

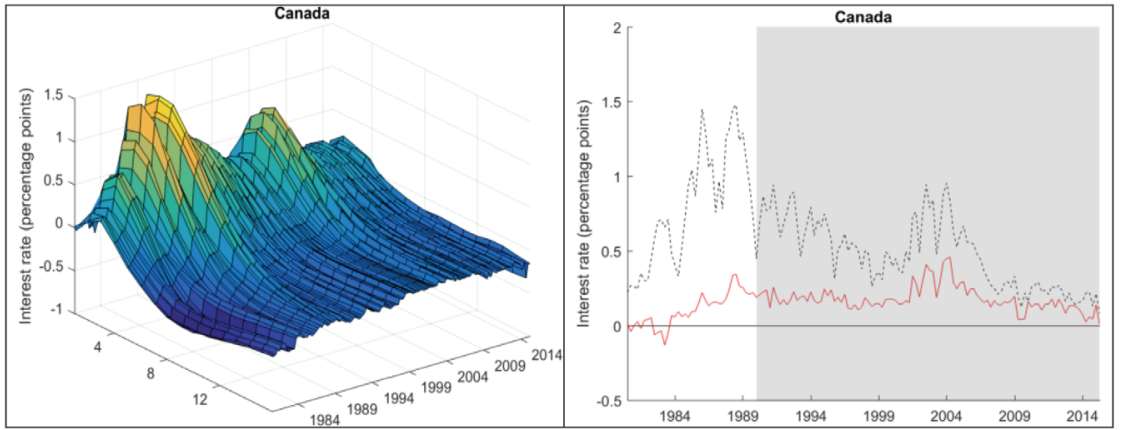

\section{Robustness Checks}

\subsection{Inclusion of the Global Financial Crisis (Post-2008 Data)}

We spelled out above four reasons for not including the post2008 period in our baseline empirical analysis (for an analysis of monetary-fiscal interactions in this period see, e.g., Tulip 2014). Nevertheless, to illustrate the effect of extending the data range, figure 7 reports the estimates for Canada, chosen due to the absence of unconventional monetary policy in the post-2008 period. The results show that our baseline findings are robust; the estimates in figures 1 and 7 are similar in terms of their changes over time.

Figure 8 presents extended estimation results for the United States as well, but the covered period is shorter (1980:Q1-2010:Q4) due to the above-discussed use of unconventional monetary policy. Comparing these results with the baseline results in figure 1, especially the scale on the vertical axis, makes clear that the inclusion of the data from the global financial crisis is undesirable. The post-2008 observations overshadow earlier developments and lead to a loss of insight (not to mention the potential estimation problems due to an increased risk premium, use of rescue packages, and quantitative easing). Nevertheless, the main finding of our baseline analysis that U.S. 


\section{Figure 8. IRFs for the United States Estimated on a Longer Sample (1980:Q1-2010:Q4)}

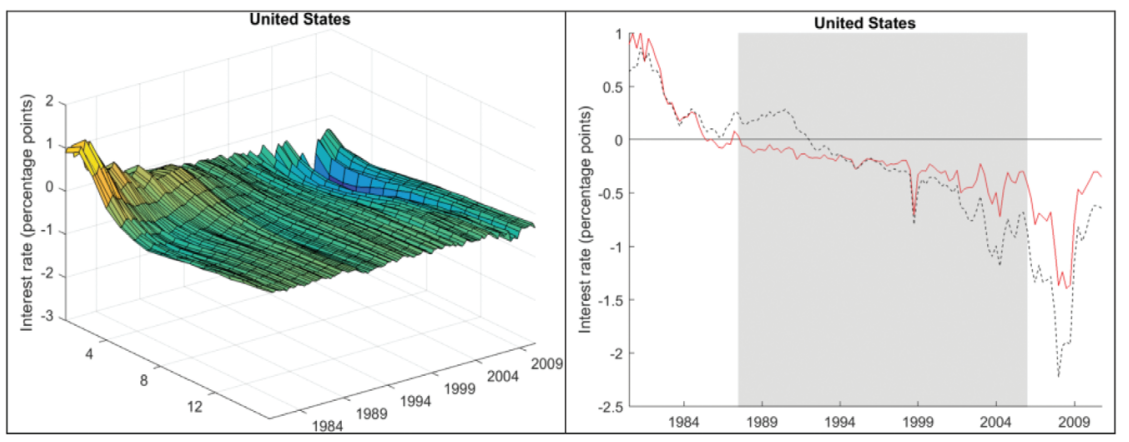

Note: The shaded area indicates Alan Greenspan's Chairmanship at the Federal Reserve.

monetary policy has become more accommodative of debt-financed fiscal shocks is still apparent 25

\subsection{Inclusion of Inflation in the TVP-VAR}

It is important to check whether our results are robust to including inflation in the set of endogenous variables - given that monetary policy decisions are linked to it. For computational reasons explained above, we need to limit the TVP-VAR analysis to five endogenous variables, which is why inflation will replace private consumption. Figure 9 presents the responses of the interest rate to a 1 percent debt-financed government spending shock, both on impact and in the third quarter.

The responses of the interest rate convey, to a large extent, the same message as our baseline results. The estimates are virtually unchanged for Japan, Switzerland, and the United Kingdom, whereas for the United States and Canada the main differences lie in the exact timing of the events and their quantitative rather than qualitative nature. In terms of the United States, figure 9 indicates that the Fed may have still maintained a slight monetary offset of

\footnotetext{
${ }^{25}$ See also Cobham (2013) for an empirical analysis of major central banks' responses to house prices in the run-up of the global financial crisis.
} 
Figure 9. IRFs of the Interest Rate on Impact (solid line) and in the Third Quarter (dotted line) to a 1 Percent Debt-Financed Government Spending Shock

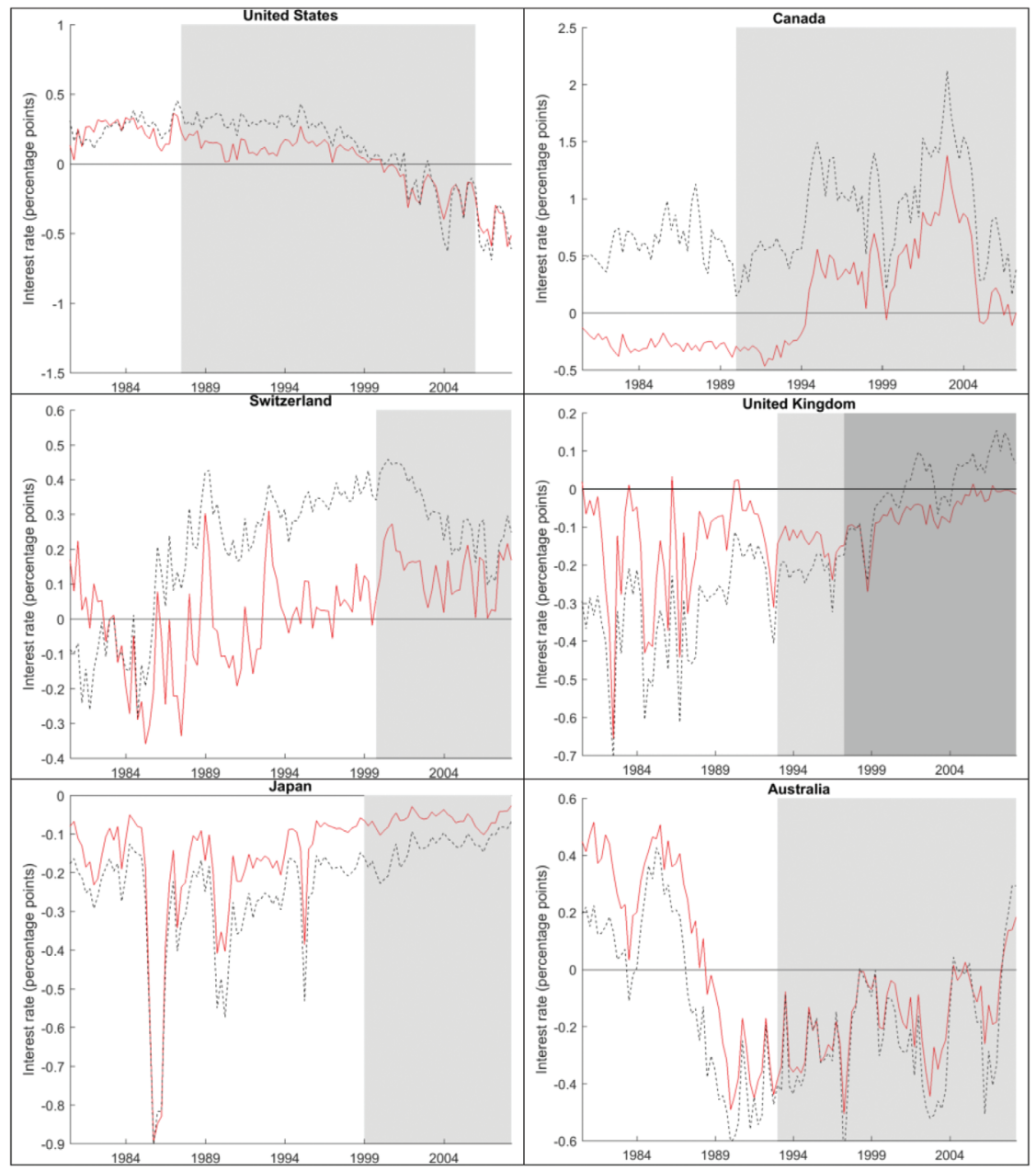

Notes: The shaded areas indicate the following: (i) Australia, Canada, and the United Kingdom: introduction of explicit inflation targets (in the latter also the subsequent granting of independence), (ii) Japan: the zero-lower bound period, (iii) United States: change of the Fed Chairman. 
fiscal shocks in the 1990s, and only moved to their accommodation in the late 1990s. Nevertheless, the gradual trend of weaker responses to debt-financed government spending is apparent from the mid1990s. Similarly, the Bank of Canada may have been slightly in the accommodative territory in the 1980s, but with the introduction of explicit inflation targeting, a regime change is apparent, marking a trend towards monetary offsetting of fiscal shocks.

Only the results for Australia provide a somewhat different picture from the baseline analysis, in that the large-scale disinflation in the late 1980s appears (not very plausibly) as a period of growing monetary accommodation. But even then the claim of conjecture 1 regarding the effect of explicit inflation targets seems to be supported, because the degree of monetary accommodation between the early 1990s and 2008 has decreased substantially.

\subsection{Monetary Policy Reaction Functions}

To check the validity of our identification procedure and of TVPVARs more generally, the following sections present robustness exercises based on single equations. The starting point is a forwardlooking Taylor-type monetary policy reaction function as introduced in Clarida, Galí, and Gertler (1998):

$$
r_{t}=(1-\rho)\left\{\alpha+\beta E\left[\pi_{t+4} \mid \Omega_{t}\right](1-\rho)+\gamma E\left[x_{t} \mid \Omega_{t}\right]\right\}+\rho r_{t-1}+v_{t},
$$

where $r_{t}$ is the short-term interest rate, $\pi_{t}$ denotes inflation, $x_{t}$ stands for the output gap, and $v_{t}$ is an exogenous random shock to the interest rate. The parameter $\rho$ captures the degree of interest rate smoothing and $\Omega_{t}$ describes the central bank's information set at time $t 26$ Assuming rational expectations, the estimation procedure draws on the following orthogonality conditions:

$$
E\left[r_{t}-(1-\rho)\left[\alpha+\beta \pi_{t+4}+\gamma x_{t}\right]-\rho r_{t-1} \mid u_{t}\right]=0,
$$

where the instrument set $u_{t}$ includes variables within the central bank's information set, $u_{t} \in \Omega_{t}$. The vector of parameters $[\alpha, \beta, \gamma, \rho]$

\footnotetext{
${ }^{26}$ In the case of Canada, the reaction function also includes the real CAD/USD exchange rate.
} 
is estimated by a two-step generalized method of moments (GMM) on the subsamples defined in section 427 In terms of the instruments, we use a vector of ones, the first four lags of inflation, the output gap, the interest rate, the growth of commodity prices, the federal funds rate, and the growth of the real exchange rate 28 Table 2 reports the estimation results.

Table 2 suggests the existence of changes in the conduct of monetary policy. For all three inflation targeters (Canada, the United Kingdom, and Australia), the coefficient on expected inflation shifts from a value of well below 1 to a value well above 1 after legislating a numerical inflation target. This means that the Taylor principle was only adhered to in the inflation-targeting era, but not before that 29

Such finding is in stark contrast to the remaining (non-targeting) countries. Most interestingly, in the United States the response to expected inflation has decreased substantially. As a result, in the second half of the sample the Fed's coefficient on expected inflation is much lower than in the three inflation-targeting countries, whereas the opposite was the case in the first part of the sample. In Switzerland the coefficient on expected inflation has not changed much and

\footnotetext{
${ }^{27}$ The estimation approach requires stationarity of regressors. The null of the unit-root presence cannot often be rejected in our case according to the augmented Dickey-Fuller test. For example, for Switzerland and Japan, no regressor seems to be stationary according to the test. However, the low power of such a test in the case of small samples suggests carrying out the GMM exercise regardless of the results of stationarity tests. Note that our subsamples contain from forty to seventy observations, and they are shortened from both sides due to the presence of leading and lagged terms in the estimated equation.

${ }^{28}$ Due to the strong trade ties between the United States and Canada, the first four lags of the CAD/USD real exchange rate are added to the set of instruments for Canada. Moreover, up to four lags of the M2 growth are added. For Switzerland, the first four lags of the three-month German interbank market rate are added, as the interlinkages between the Swiss and German financial markets play an important role for Swiss monetary policy. For the United States, the four lags of the real exchange rate growth are replaced by four lags of the spread between the ten-year Treasury constant maturity and the federal funds rate. The first four lags of M2 growth are also included.

${ }^{29}$ In the pre-inflation-targeting part of the sample, the estimate of the value of the coefficient on expected inflation being below unity is statistically significant for all three targeters. The opposite finding of the Taylor principle being satisfied post-adoption of explicit inflation targets is, however, not statistically significant, which is probably a consequence of weak instruments (see appendix 5).
} 
Table 2. Monetary Policy Reaction Functions
Using a Two-Step GMM

\begin{tabular}{|c|c|c|c|c|}
\hline & $\boldsymbol{\beta}$ & $\gamma$ & $\rho$ & J-stat. \\
\hline \multicolumn{5}{|c|}{ United States } \\
\hline $\begin{array}{l}\text { 1980:Q1-1992:Q4 } \\
\text { 1993:Q1-2008:Q2 }\end{array}$ & $\begin{array}{c}3.33 \\
(0.61) \\
1.51 \\
(1.45)\end{array}$ & $\begin{array}{l}0.5 \\
(0.46) \\
1.98 \\
(0.38)\end{array}$ & $\begin{array}{c}0.89 \\
(0.04) \\
0.91 \\
(0.03)\end{array}$ & $\begin{array}{c}8.39 \\
0.8127 \\
8.71 \\
0.7941\end{array}$ \\
\hline \multicolumn{5}{|c|}{ Switzerland } \\
\hline $\begin{array}{l}\text { 1980:Q1-1992:Q4 } \\
\text { 1993:Q1-2008:Q2 }\end{array}$ & $\begin{array}{c}0.93 \\
(0.09) \\
1.06 \\
(0.21)\end{array}$ & $\begin{array}{c}1.26 \\
(0.21) \\
1.37 \\
(0.20)\end{array}$ & $\begin{array}{c}0.68 \\
(0.04) \\
0.87 \\
(0.01)\end{array}$ & $\begin{array}{c}10.33 \\
0.9957 \\
11.15 \\
0.9922\end{array}$ \\
\hline \multicolumn{5}{|c|}{ Japan } \\
\hline $\begin{array}{l}\text { 1980:Q1-1992:Q4 } \\
\text { 1993:Q1-2008:Q2 }\end{array}$ & $\begin{array}{c}0.65 \\
(0.24) \\
0.04 \\
(0.08)\end{array}$ & $\begin{array}{c}1.88 \\
(0.29) \\
0.42 \\
(0.10)\end{array}$ & $\begin{array}{c}0.82 \\
(0.03) \\
0.91 \\
(0.01)\end{array}$ & $\begin{array}{c}10.29 \\
0.9749 \\
9.44 \\
0.9853\end{array}$ \\
\hline \multicolumn{5}{|c|}{ Canada } \\
\hline $\begin{array}{l}\text { 1981:Q1-1990:Q4 } \\
\text { 1991:Q1-2008:Q2 }\end{array}$ & $\begin{array}{c}-1.96 \\
(0.15) \\
1.97 \\
(0.88)\end{array}$ & $\begin{array}{c}0.73 \\
(0.03) \\
1.98 \\
(0.35)\end{array}$ & $\begin{array}{c}0.81 \\
(0.00) \\
0.9 \\
(0.02)\end{array}$ & $\begin{array}{c}7.09 \\
0.9999 \\
13.39 \\
0.9910\end{array}$ \\
\hline \multicolumn{5}{|c|}{ United Kingdom } \\
\hline $\begin{array}{l}\text { 1980:Q1-1992:Q4 } \\
\text { 1993:Q1-2008:Q2 }\end{array}$ & $\begin{array}{c}0.46 \\
(0.18) \\
2.63 \\
(1.16)\end{array}$ & $\begin{array}{c}1.53 \\
(0.32) \\
9.23 \\
(3.97)\end{array}$ & $\begin{array}{c}0.8 \\
(0.04) \\
0.93 \\
(0.03)\end{array}$ & $\begin{array}{c}8.84 \\
0.9904 \\
11.53 \\
0.9513\end{array}$ \\
\hline \multicolumn{5}{|c|}{ Australia } \\
\hline $\begin{array}{l}\text { 1980:Q1-1992:Q4 } \\
\text { 1993:Q1-2008:Q2 }\end{array}$ & $\begin{array}{c}0.64 \\
(0.07) \\
3.16 \\
(1.73)\end{array}$ & $\begin{array}{c}1.51 \\
(0.15) \\
-0.22 \\
(1.35)\end{array}$ & $\begin{array}{c}0.69 \\
(0.02) \\
0.95 \\
(0.02)\end{array}$ & $\begin{array}{c}9.76 \\
0.9819 \\
10.45 \\
0.9725\end{array}$ \\
\hline \multicolumn{5}{|c|}{$\begin{array}{l}\text { Notes: Standard errors are reported in parentheses; the p-value is reported below the } \\
\text { J-statistic. Headline CPI inflation is used (except Canada and the United Kingdom, where } \\
\text { core inflation is used). Output gaps are computed using the HP filter with the smoothing } \\
\text { parameter equal to } 1600 \text { except for the United States (where the Congressional Budget } \\
\text { Office's estimate is used) and Canada (where the Bank of Canada's estimate is used). The } \\
\text { commodity price growth is the annual change of the producer price index for all commodi- } \\
\text { ties. The real exchange rate growth is the log-difference of the real effective exchange rate } \\
\text { based on the manufacturing consumer price index. All data are taken from the Federal } \\
\text { Reserve Economic Data (FRED) database. }\end{array}$} \\
\hline
\end{tabular}


is around 1. In Japan it has decreased to a value close to 0, which is expected given its zero lower bound constraint 30

These results support the nature of our baseline findings and suggest that an appropriate methodology must include possibility of changes in the policy stance over time to capture real-world developments.

\subsection{Extended Monetary Policy Reaction Function (Featuring Fiscal Shocks) for the United States}

Here we add fiscal shocks into the empirical specification of the previous section. The fiscal shocks are extracted using the so-called narrative approach, namely a defense news shock constructed by Ramey (2016). In particular, the following model is used:

$r_{t}=(1-\rho)\left\{\alpha+\beta E\left[\pi_{t+4} \mid \Omega_{t}\right]+\gamma E\left[x_{t} \mid \Omega_{t}\right]+\xi E\left[z_{t} \mid \Omega_{t}\right]\right\}+\rho r_{t-1}+v_{t}$,

where $z_{t}$ stands for one of the following variables: fiscal shock, money growth, and lagged inflation. In using the latter two variables we follow Clarida, Galí, and Gertler (1998). The results are presented in table 3.

Table 3 shows that additional regressors in the U.S. monetary policy rule do not alter our key finding about a decline in the Fed's inflation focus over time. Furthermore, the fiscal shock seems to be important in both subsamples. The estimates imply that an expected change in defense spending of the size of 1 percent of lagged nominal GDP was (on average) followed by a 1.43 percentage point increase of the federal funds rate during 1980:Q1-1992:Q4, but by a 3.05 percentage point decrease in the 1993:Q1-2008:Q2 period. This shows that in the former period monetary policy tended to offset fiscal shocks, whereas in the latter period it accommodated them.

Caution, however, needs to be exercised in interpreting these additional results, as there appear some econometric issues related to the employed methodology, well-documented in the literature.

\footnotetext{
${ }^{30}$ Let us mention that our estimates are broadly in line with those of others. For example, based on U.S. quarterly data over the 1979:Q3-1996:Q4 period, Clarida, Galí, and Gertler (2000) found the coefficient on expected inflation and the output gap to equal 2.15 and 0.93 , respectively.
} 
Table 3. Extended Monetary Policy Reaction Function for the United States

\begin{tabular}{|c|c|c|c|c|c|}
\hline & $\boldsymbol{\beta}$ & $\gamma$ & $\rho$ & $\xi$ & J-stat. \\
\hline \multicolumn{6}{|c|}{ Benchmark (Model of Section 6.3) } \\
\hline $\begin{array}{l}\text { 1980:Q1-1992:Q4 } \\
\text { 1993:Q1-2008:Q2 }\end{array}$ & $\begin{array}{c}3.33 \\
(0.61) \\
1.51 \\
(1.45)\end{array}$ & $\begin{array}{c}0.5 \\
(0.46) \\
1.98 \\
(0.38)\end{array}$ & $\begin{array}{c}0.89 \\
(0.04) \\
0.91 \\
(0.03)\end{array}$ & & $\begin{array}{c}8.39 \\
0.8127 \\
8.71 \\
0.7941\end{array}$ \\
\hline \multicolumn{6}{|c|}{ Money Growth } \\
\hline $\begin{array}{l}\text { 1980:Q1-1992:Q4 } \\
\text { 1993:Q1-2008:Q2 }\end{array}$ & $\begin{array}{c}4.24 \\
(1.54) \\
0.49 \\
(1.14)\end{array}$ & $\begin{array}{c}0.73 \\
(0.93) \\
2.24 \\
(0.59)\end{array}$ & $\begin{array}{c}0.93 \\
(0.04) \\
0.9 \\
(0.04)\end{array}$ & $\begin{array}{c}-13.65 \\
(10.41) \\
-9.62 \\
(4.42)\end{array}$ & $\begin{array}{c}8.27 \\
0.9404 \\
10.16 \\
0.8579\end{array}$ \\
\hline \multicolumn{6}{|c|}{ Lagged Inflation } \\
\hline $\begin{array}{l}\text { 1980:Q1-1992:Q4 } \\
\text { 1993:Q1-2008:Q2 }\end{array}$ & $\begin{array}{c}3.53 \\
(1.48) \\
0.56 \\
(0.9)\end{array}$ & $\begin{array}{c}0.5 \\
(0.48) \\
1.69 \\
(0.22)\end{array}$ & $\begin{array}{c}0.89 \\
(0.04) \\
0.89 \\
(0.03)\end{array}$ & $\begin{array}{c}-0.09 \\
(0.56) \\
1.24 \\
(0.51)\end{array}$ & $\begin{array}{c}8.1 \\
0.7776 \\
7.04 \\
0.8548\end{array}$ \\
\hline \multicolumn{6}{|c|}{ Defense News } \\
\hline $\begin{array}{l}\text { 1980:Q1-1992:Q4 } \\
\text { 1993:Q1-2008:Q2 }\end{array}$ & $\begin{array}{c}2.53 \\
(0.46) \\
1.21 \\
(1.07) \\
\end{array}$ & $\begin{array}{c}1.04 \\
(0.31) \\
1.39 \\
(0.14) \\
\end{array}$ & $\begin{array}{c}0.89 \\
(0.02) \\
0.89 \\
(0.03) \\
\end{array}$ & $\begin{array}{c}1.43 \\
(0.39) \\
-3.05 \\
(0.83) \\
\end{array}$ & $\begin{array}{c}9.94 \\
0.9916 \\
10.84 \\
0.9848 \\
\end{array}$ \\
\hline \multicolumn{6}{|c|}{$\begin{array}{l}\text { Notes: Standard errors are reported in parentheses; the p-value is reported below the } \\
\text { J-statistic. Data are taken from the FRED database except the defense news, which } \\
\text { are from Ramey (2016) as a percentage of lagged nominal GDP. Money growth is the } \\
\text { quarterly average of month-on-month growth of M2. Lagged inflation is represented } \\
\text { by the first lag of year-on-year CPI change. }\end{array}$} \\
\hline
\end{tabular}

They include small-sample properties of GMM estimators (e.g., Jondeau, Le Bihan, and Galles 2014) and weak instruments (e.g., Stock, Wright, and Yogo 2002 or Mavroeidis 2010). An in-depth analysis of such issues is beyond the scope of this robustness exercise, but some relevant results and comments regarding the strength of the instruments are offered in appendix 3. 


\subsection{Using a Narrative Measure of Monetary Policy Shocks}

A natural extension of employing a narrative measure of government spending is to examine the relationship between monetary and fiscal shocks directly, i.e., without imposing any dynamics even within a single-equation framework. To that end, we take the narrative measures of both policies' shocks in the United States and examine their linkages over our subsamples.

Together with Ramey's (2016) defense news shocks, we use monetary policy shocks constructed by Romer and Romer (2004) and extended until 2007:Q4 by Wieland and Yang (2016) 31 The narrative measure of monetary policy shocks is constructed such that the intended federal funds rate, derived from the Fed's reports, is adjusted by the estimated monetary reaction to the economic situation - as captured by the Fed's internal forecasts. What is left after taking into account the forecast is the monetary policy shock.

The two sets of narrative-type shocks are used in a simple linear model, which regresses monetary policy shocks (only) on fiscal shocks using OLS, separately on the 1980:Q1-1992:Q4 and 1993:Q12007:Q4 subsamples. While the coefficient on the defense news shock is not statistically significant for the earlier period, for the later period it is (the p-value being 0.07). Quantitatively, between 1993 and 2008 an expected increase in fiscal (defense) spending in the value of 1 percent of lagged nominal GDP decreased the monetary policy rate by 9 basis points on average. Such reaction by the Fed was the systematic response over and above what is contained in their internal forecasts used for the construction of narrative shocks, which is why its magnitude is naturally much lower than that of the previous section. This result provides further evidence of a more accommodative stance of U.S. monetary policy to fiscal shocks in the 1990s and 2000s, in line with our baseline findings.

\section{Conclusions: Is Unpleasant Monetarist Arithmetic To Be Feared?}

It is now widely accepted that monetary and fiscal policies are interlinked even if the central bank is formally independent of the

\footnotetext{
${ }^{31}$ The data are kindly provided by Johannes Wieland at https://sites.google. com/site/johannesfwieland.
} 
government. This is because the actions of each policy affect many important economic variables and these variables in turn affect the actions of both policies. The paper's primary aim was to track monetary-fiscal interactions over time and across six advanced countries in order to contribute to our understanding of the relationship between the two policies. Our secondary aim was to use this understanding in assessing the medium- and long-term danger of an unpleasant monetarist arithmetic - the concerns that fiscal excesses may spill over to monetary policy and result in departures from price stability.

We do so using an empirical framework that combines timevarying parameter vector autoregression with the sign-restrictions identification procedure. Having first discussed the advantages of this framework vis-à-vis the standard fixed-parameter VARs and/or the recursive identification method, we then report how monetary policy responses to debt-financed government spending shocks have changed since 1980 .

It is shown that while in the United States monetary policy responses to debt-financed fiscal shocks have become more accommodative over time, the opposite seems to have been the case in Australia, Canada, Switzerland, and the United Kingdom.

Our subsequent analysis explores one possible institutional reason for some of the observed changes and country differences, namely adoption of numerical inflation targets. We provide some evidence that such a commitment gives the central bank more ammunition in dealing with the government's excessive spending. This implies that numerical inflation targets may be able to discipline both policies, i.e., they may lower the degree of monetary accommodation of fiscal shocks as well as induce a reduction in long-term fiscal imbalances.

While we offer several robustness checks that support our baseline results, the presented evidence is still not conclusive. It is insufficient to unambiguously confirm our two conjectures and, more generally, the fact that an institutional reform of one policy may have positive effects on the other policy through strategic interactions. More research is thus required to shed light on the many specific channels through which monetary and fiscal policies interact with each other. This is of particular importance in the current situation of large (demographics-driven) fiscal imbalances facing advanced countries in the decades to come. 
Keeping these limitations in mind, our analysis implies some tentative predictions in regards to the probability of Sargent and Wallace's (1981) unpleasant monetarist arithmetic. They are based not only on all our baseline and auxiliary results but also on the trends in intertemporal fiscal imbalances and strength of the legislated commitment to low inflation (see figure 2). All these results imply that the likelihood of undesirable long-term spillovers from fiscal onto monetary policy is the lowest in Australia and Canada, somewhat higher in the United Kingdom and Switzerland, and the highest in the United States and Japan.

In particular, Australia and Canada appear to operate within the monetary-dominance regime of active monetary and passive fiscal policy, so an unpleasant monetarist arithmetic seems unlikely. This is in contrast to the United States and Japan, both of which seem to be stuck within a fiscal-dominance regime. In this regime, monetary policy passively accommodates active fiscal policy, so fiscal inflation due to debt monetization is much more likely in the future (once demographic pressures intensify). Switzerland and the United Kingdom seem to be somewhere in between, as neither policy dominates the other. Because of that, a costly tug-of-war between their central banks and governments may eventuate in the future.

Overall, our analysis suggests that the danger of advanced countries experiencing an unpleasant monetarist arithmetic should not be underestimated. More research will hopefully improve our understanding of monetary-fiscal interactions that is crucial in designing welfare enhancing institutional reforms of the two policies.

\section{Appendix 1. Gibbs Sampler}

The specification of the sampling algorithm and parameters of prior distributions mostly follows Cogley and Sargent (2005), Primiceri (2005), Kirchner, Cimadomo, and Hauptmeier (2010), and Pereira and Lopes (2010).

\section{Priors}

The prior distribution of the initial states $\alpha_{i, 0}, \beta_{i, 0}, \log \left(\sigma_{i, 0}\right)$ is normal with means given by the corresponding OLS estimates on the whole data sample. Assumed prior variances are proportional to the 
estimated OLS variances for coefficients and to the identity matrix for the volatility states:

$$
\begin{gathered}
\beta_{i, 0} \sim N\left(\beta_{i, 0}^{O L S}, 4 \operatorname{Var}\left(\beta_{i}^{O L S}\right)\right), \\
\alpha_{i, 0} \sim N\left(\alpha_{i, 0}^{O L S}, 4 \operatorname{Var}\left(\alpha_{i}^{O L S}\right)\right), \\
\log \left(\sigma_{i, 0}\right) \sim N\left(\log \left(\sigma_{i}^{O L S}\right), 10 I_{5}\right) .
\end{gathered}
$$

The hyperparameter $U$ and blocks of $V$ are distributed as inverseWishart distribution:

$$
\begin{gathered}
U \sim I W\left(k_{Q}^{2} \tau \operatorname{Var}\left(\beta^{O L S}\right), \tau\right), \\
V_{b l} \sim I W\left(k_{V}^{2}\left(1+\operatorname{dim}\left(V_{b l}\right)\right) \operatorname{Var}\left(A_{b l}^{O L S}\right), 1+\operatorname{dim}\left(V_{b l}\right)\right), \\
b l=1, \ldots, 4
\end{gathered}
$$

where $k_{Q}=0.01$ and $k_{V}=0.1$. These parameters represent our prior beliefs on the proportion of uncertainty of the OLS estimate attributed to time-variation of the VAR coefficients and elements of the matrix $A$. The "degrees of freedom" parameter $\tau$ is 5032 The diagonal elements of $W$ are distributed as inverse-Gamma (see Kirchner, Cimadomo, and Hauptmeier 2010):

$$
W_{i}=I G\left(\frac{k_{w}^{2}}{2}, \frac{1}{2}\right), \text { where } k_{W}=0.01 .
$$

\section{Estimation Procedure}

The Gibbs sampler exploits the fact that draws from the conditional distributions of the subsets of the model parameters (given the rest of the parameter set) represent a sample from the joint posterior distribution. The sampler can then be described in the following steps:

- The vector of coefficient states $\beta$ is estimated using the Carter and Kohn (1994) algorithm. For given data and the history of the covariance and volatility states, equations (11) and (2)

\footnotetext{
${ }^{32}$ For Canada estimated for the 1981-2016 period, we increase the "degrees of freedom" parameter by the number of observations to make the prior tighter.
} 
represent a linear Gaussian system with a known covariance matrix.

- Covariance states stacked in the matrix $A_{t}$ are also estimated employing the algorithm of Carter and Kohn (1994). Equation

(1) implies that

$$
\hat{y}_{t}=A_{t}\left(y_{t}-X_{t} \beta_{t}\right)=\Sigma_{t} \varepsilon_{t}
$$

i.e., given data and the history of coefficient and volatility states, we again obtain a linear Gaussian system. The algorithm is applied equation by equation so it yields draws of the covariance states stacked below the diagonal of $A_{t}$ in turns.

- To draw volatility states, we follow Cogley and Sargent (2005) 33 Given data and the history of the coefficient and covariance states, the right-hand side of (6) is observable. Assuming diagonality of the hyperparameter $W$, volatility states can be drawn as in Jacquier, Polson, and Rossi (1994), that is, a univariate algorithm is applied on the orthogonalized residuals element by element. Jacquier, Polson, and Rossi (1994) describe a Metropolis step that produces a draw (if accepted) from the conditional posterior distribution for a volatility state.

- Finally, given the data, coefficient states, and covariance and volatility states, the innovations in (2)-(4) are observable. Priors on hyperparameters are distributed as inverse-Wishart (inverse-Gamma), thus posterior distributions take the same type of distribution and drawing of the hyperparameters is straightforward.

\section{Appendix 2. Convergence Diagnostics}

The convergence of the sequence of draws to a posterior distribution is assessed by two measures based on the autocorrelation of draws and by the diagnostics suggested by Raftery and Lewis (1992) 34 The first measure is a simple autocorrelation of draws from the

\footnotetext{
${ }^{33}$ This avoids the problem discussed in Del Negro and Primiceri (2014).

${ }^{34}$ The same convergence diagnostics as in Primiceri (2005) are presented. The implementation in MATLAB draws on the Econometrics Toolbox discussed in LeSage (1999).
} 


\section{Figure 10. Autocorrelation, Inefficiency Factors, and the Raftery and Lewis Statistic for Model Parameters in Australia for 1985:Q1}

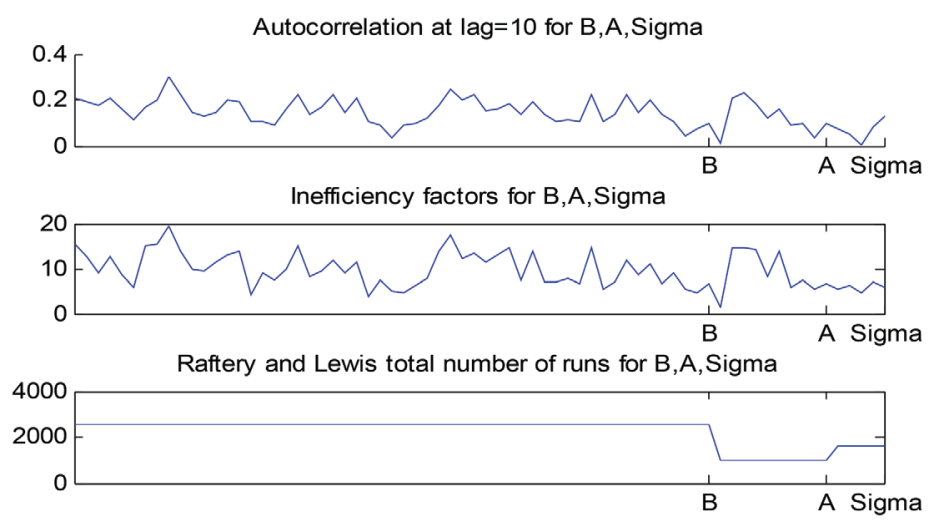

conditional posterior distributions with a lag equal to 10. Low autocorrelation suggests efficiency of the sampling algorithm. A more sophisticated measure based on sample autocorrelations takes into account autocorrelations at all possible lags. It is referred to as the "inefficiency factor" and defined as $1+2 \sum_{k=1}^{\infty} \rho_{k}$, with $\rho_{k}$ denoting the $\mathrm{k}$-th autocorrelation of the chain of draws. Primiceri (2005) suggests that values of the inefficiency factor below 20 can be viewed as satisfactory. Finally, Raftery and Lewis (1992) introduced a statistic that provides the number of draws ensuring a certain level of precision 35

Due to a high number of parameters, figure 10 presents the convergence diagnostics only for Australia, and only for the coefficients related to an arbitrarily chosen period 1985:Q1. For other countries and periods, the convergence statistics look very similar.

The statistics presented in figure 10 suggest a sufficient convergence of the Markov chain Monte Carlo algorithm for parameters: autocorrelation of the chain is low, inefficiency factors achieve values below 20, and the suggested number of runs is lower than 4,000. The hyperparameters are reported in figures 11-13.

\footnotetext{
${ }^{35}$ In this paper, for the 0.025 and 0.975 quantiles of marginal posterior distributions, the desired accuracy of 0.025 is required to be achieved with probability 0.95 .
} 
Figure 11. Autocorrelation of the Chain for the Hyperparameters $U, V$, and $W$

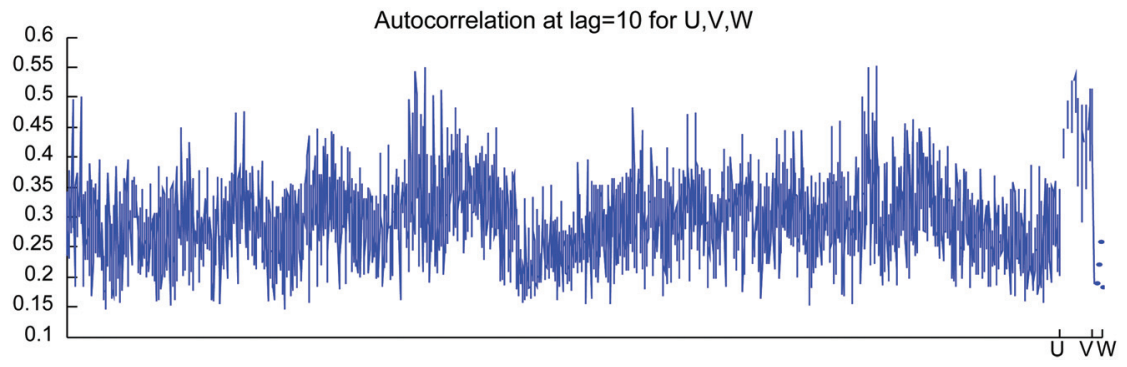

Figure 12. Inefficiency Factors for the Hyperparameters $U, V$, and $W$

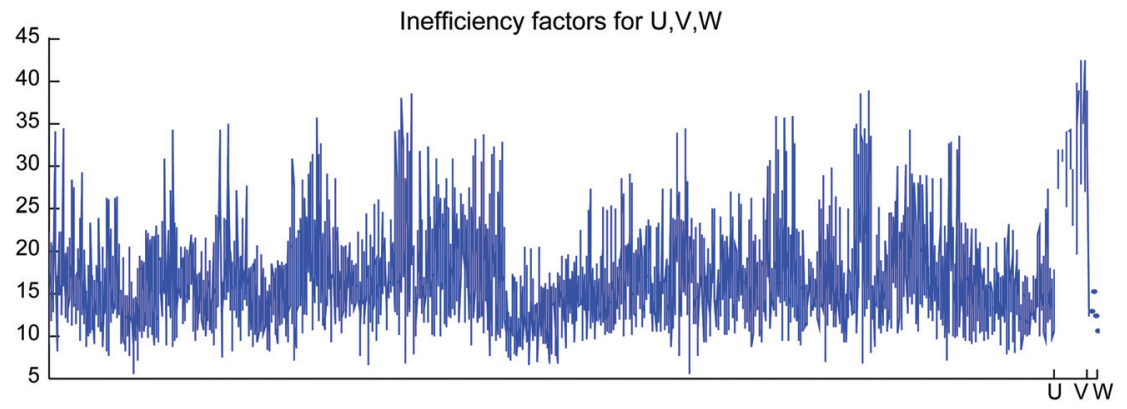

Figure 13. Raftery and Lewis Statistics for the Hyperparameters $U, V$, and $W$

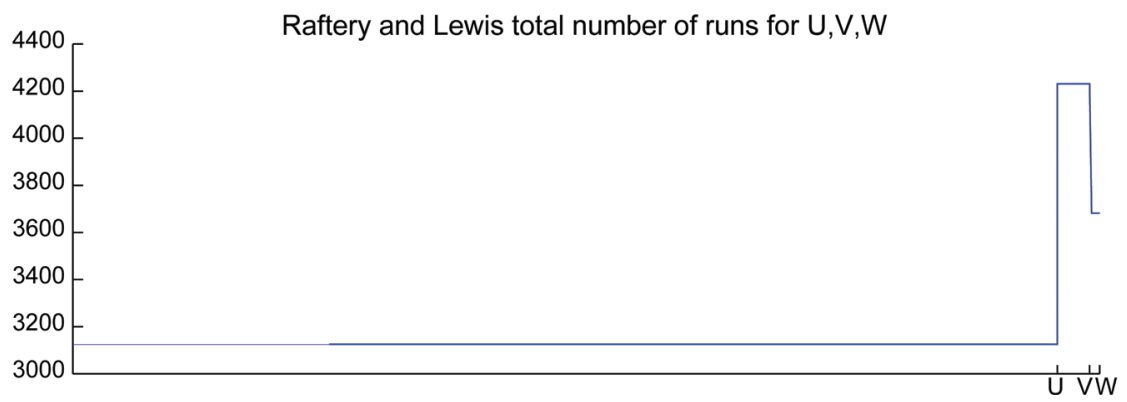




\section{Appendix 3. Further Discussion of Robustness}

\section{Anticipation Effects}

Government spending shocks are often anticipated by agents because of implementation and legislative lags. Anticipation effects of fiscal policy can be related to the timing of a spending shock (Ramey 2011) or the way future fiscal adjustment will be carried out (Leeper, Walker, and Yang 2010).

The identification approach used in this paper can deal with the first type of anticipation effects similarly to Mountford and Uhlig (2009), who account for "announcement effects" by imposing a positive sign on their fiscal variable after four quarters. For the first four quarters, the fiscal variable is assumed to be inert and the prescribed signs of other responses do not change. Using U.S. data, Mertens and Ravn (2010) demonstrate that anticipation effects of spending shocks do not determine the sign of the output reaction. Therefore, our identification approach is not affected by the presence of such type of anticipation effects.

The latter type of anticipation effects - agents' expectations of the way current fiscal shortfalls are reversed by the future fiscalmonetary mix - could in principle be an issue for our identification strategy. This would be the case if different expected ways of a fiscal adjustment affected the macroeconomy differently and satisfied the same set of identification restrictions. Nevertheless, in our analysis the problem is partially mitigated by our strict focus on debt-financed spending. Furthermore, one of our robustness exercises shows that a change in the number of quarters for which the magnitude restriction is imposed changes the magnitude and profile of impulse responses only marginally.

\section{Priors}

Another robustness exercise suggests that the length of the sign restrictions affects the magnitudes of the responses to some extent. Similarly to Primiceri (2005), we find the results to be robust to the choice of priors for the variance of the initial states. We also find that our prior belief for the parameter $U$, which drives how much coefficients can differ between adjacent periods, influences significantly 
the posterior variation of coefficients and thus the resulting impulse responses. Nevertheless, our prior belief reflected by the parameter is that changes in the economy and coefficients are gradual.

\section{Instruments}

The problem of weak instruments arises when only a small portion of the variation of an endogenous variable is predictable by the instrument. The consequence is generally unreliable inference. Stock, Wright, and Yogo (2002) mention several possible manifestations of weak instruments, such as the difference between the two-step and the iterated GMM estimators, as well as sensitivity to adding instruments or changing the sample. To shed some light on the possible presence of weak instruments, we reestimate the model in section 6.4 using an iterative GMM. The results are presented in table 4.

Table 4 shows that estimates can differ somewhat from those in table 2 that use a two-step GMM. This could signal presence of weak instruments 36 Nevertheless, our key findings regarding increased monetary accommodation in the United States and the effect of explicit inflation targets seem to remain unchanged. More generally, all our results suggest that the reaction of monetary policy to fiscal shocks has changed over time, and support the use of a modeling framework such as the TVP-VAR that allows for such changes.

\footnotetext{
${ }^{36}$ There exist procedures robust to weak identification (e.g., Kleibergen 2005), based on a continuously updated GMM objective function. Its optimization is, however, numerically unstable in our case. We therefore use the two-step and iterative GMM methods.
} 
Table 4. Monetary Policy Reaction Functions
Using Iterative GMM

\begin{tabular}{|c|c|c|c|c|}
\hline & $\boldsymbol{\beta}$ & $\gamma$ & $\rho$ & J-stat. \\
\hline \multicolumn{5}{|c|}{ United States } \\
\hline $\begin{array}{l}\text { 1980:Q1-1992:Q4 } \\
\text { 1993:Q1-2008:Q2 }\end{array}$ & $\begin{array}{c}9.44 \\
(2.62) \\
-0.14 \\
(0.39)\end{array}$ & $\begin{array}{c}-0.67 \\
(0.75) \\
1.58 \\
(0.10)\end{array}$ & $\begin{array}{c}0.92 \\
(0.03) \\
0.79 \\
(0.04)\end{array}$ & $\begin{array}{c}7.91 \\
0.8494 \\
9.05 \\
0.7688\end{array}$ \\
\hline \multicolumn{5}{|c|}{ Switzerland } \\
\hline $\begin{array}{l}\text { 1980:Q1-1992:Q4 } \\
\text { 1993:Q1-2008:Q2 }\end{array}$ & $\begin{array}{l}1.12 \\
(0.06) \\
1.25 \\
(0.22)\end{array}$ & $\begin{array}{c}0.59 \\
(0.18) \\
0.81 \\
(0.23)\end{array}$ & $\begin{array}{l}0.6 \\
(0.03) \\
0.9 \\
(0.01)\end{array}$ & $\begin{array}{c}10.1 \\
0.9964 \\
10.51 \\
0.9950\end{array}$ \\
\hline \multicolumn{5}{|c|}{ Japan } \\
\hline $\begin{array}{l}\text { 1980:Q1-1992:Q4 } \\
\text { 1993:Q1-2008:Q2 }\end{array}$ & $\begin{array}{c}-1.53 \\
(1.65) \\
0.34 \\
(0.11)\end{array}$ & $\begin{array}{c}0.82 \\
(1.34) \\
-0.09 \\
(0.12)\end{array}$ & $\begin{array}{c}0.94 \\
(0.03) \\
0.93 \\
(0.01)\end{array}$ & $\begin{array}{c}9.33 \\
0.9864 \\
8.54 \\
0.9924\end{array}$ \\
\hline \multicolumn{5}{|c|}{ Canada } \\
\hline $\begin{array}{l}\text { 1981:Q1-1990:Q4 } \\
\text { 1991:Q1-2008:Q2 }\end{array}$ & $\begin{array}{c}-1.67 \\
(0.22) \\
1.06 \\
(0.21)\end{array}$ & $\begin{array}{c}0.65 \\
(0.02) \\
1.13 \\
(0.08)\end{array}$ & $\begin{array}{c}0.65 \\
(0.00) \\
0.8 \\
(0.01)\end{array}$ & $\begin{array}{c}6.85 \\
1.000 \\
12.3 \\
0.9955\end{array}$ \\
\hline \multicolumn{5}{|c|}{ United Kingdom } \\
\hline $\begin{array}{l}\text { 1980:Q1-1992:Q4 } \\
\text { 1993:Q1-2008:Q2 }\end{array}$ & $\begin{array}{c}-0.01 \\
(0.12) \\
1.61 \\
(4.03)\end{array}$ & $\begin{array}{c}2.53 \\
(0.27) \\
14.99 \\
(23.71)\end{array}$ & $\begin{array}{c}0.74 \\
(0.03) \\
0.99 \\
(0.02)\end{array}$ & $\begin{array}{c}8.74 \\
0.9911 \\
11.66 \\
0.9482\end{array}$ \\
\hline \multicolumn{5}{|c|}{ Australia } \\
\hline $\begin{array}{l}\text { 1980:Q1-1992:Q4 } \\
\text { 1993:Q1-2008:Q2 }\end{array}$ & $\begin{array}{c}0.68 \\
(0.07) \\
1.19 \\
(0.27)\end{array}$ & $\begin{array}{c}1.93 \\
(0.34) \\
-0.91 \\
(0.47)\end{array}$ & $\begin{array}{c}0.77 \\
(0.02) \\
0.88 \\
(0.02)\end{array}$ & $\begin{array}{c}9.31 \\
0.9866 \\
9.7 \\
0.9825\end{array}$ \\
\hline \multicolumn{5}{|c|}{$\begin{array}{l}\text { Notes: Standard errors are reported in parentheses; the p-value is reported below the } \\
\text { J-statistic. Headline CPI inflation is used (except Canada and the United Kingdom, where } \\
\text { core inflation is used). Output gaps are computed using the HP filter with the smoothing } \\
\text { parameter equal to } 1600 \text { except for the United States (where the Congressional Budget } \\
\text { Office's estimate is used) and Canada (where the Bank of Canada's estimate is used). The } \\
\text { commodity price growth is the annual change of the producer price index for all com- } \\
\text { modities. The real exchange rate growth is the log-difference of the real effective exchange } \\
\text { rate based on the manufacturing consumer price index. All data are taken from the FRED } \\
\text { database. }\end{array}$} \\
\hline
\end{tabular}




\section{Appendix 4. IRFs to a Debt-Financed Government Spending Shock for All Countries and Variables at Two Horizons}

As explained above, in order to keep our focus we do not include an in-depth discussion of results other than relating to monetaryfiscal policy interactions. A selection of the results - namely impulse responses on impact and the third quarter - appears in figures 14-19.

Figure 14. United States-IRF on Impact and in the Third Quarter
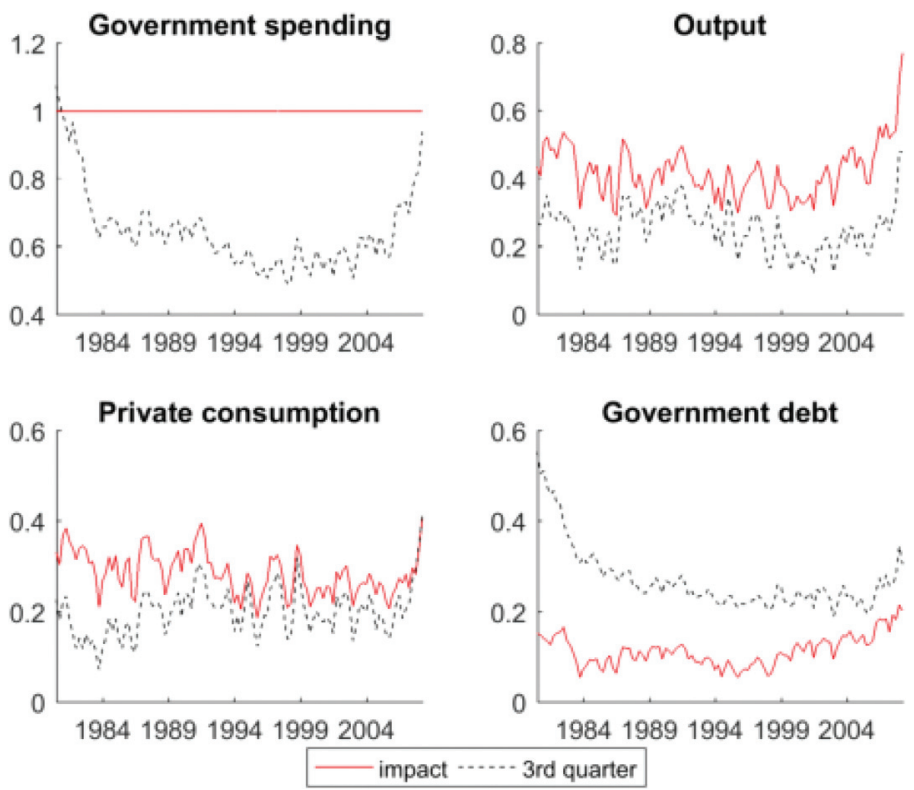
Figure 15. Canada-IRF on Impact and in the Third Quarter
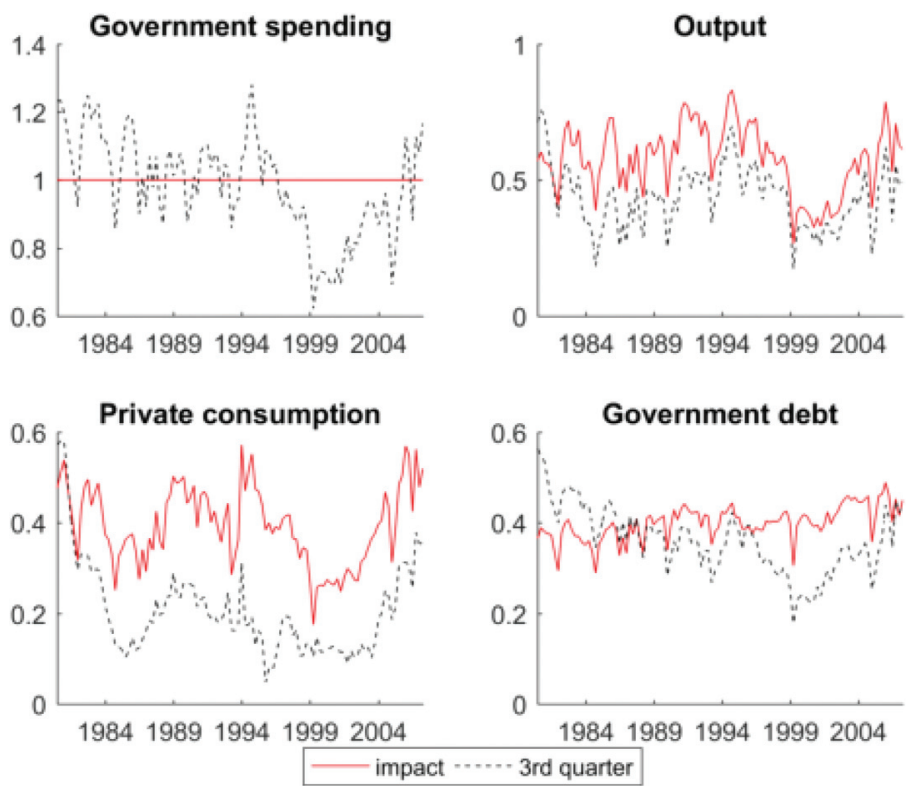

Figure 16. Switzerland-IRF on Impact and in the Third Quarter
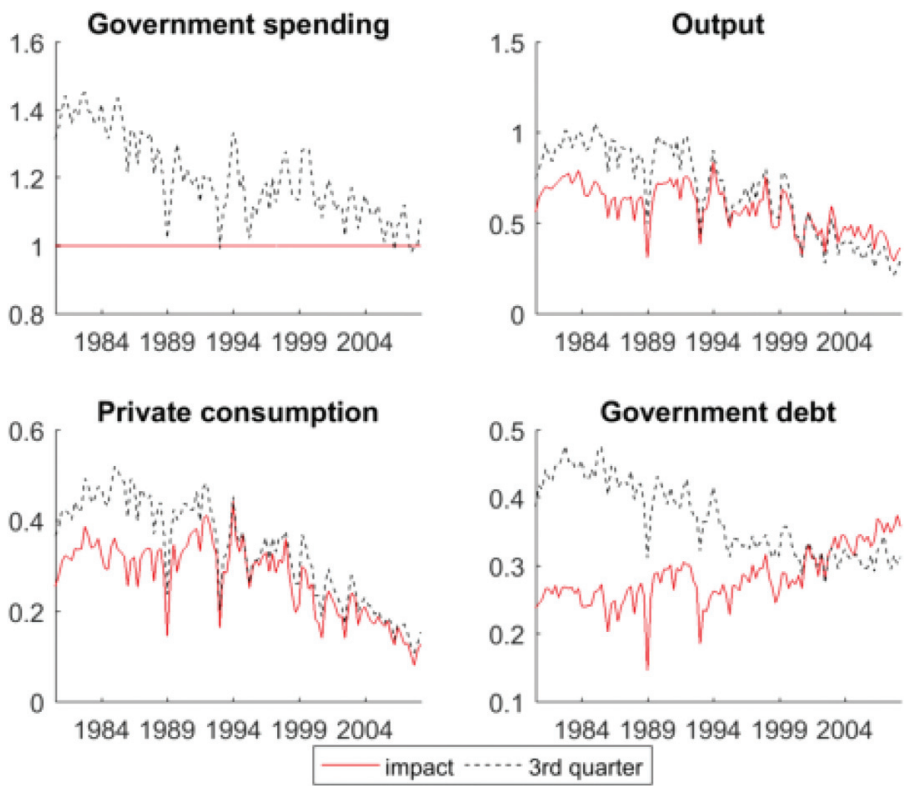
Figure 17. United Kingdom-IRF on Impact and in the Third Quarter
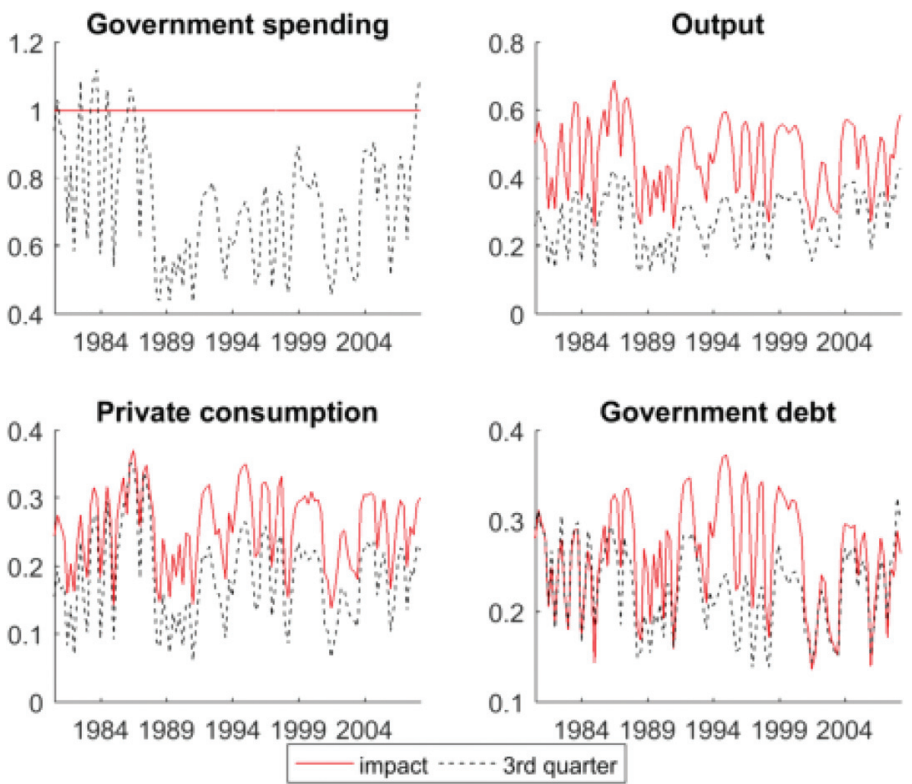

Figure 18. Japan-IRF on Impact and in the Third Quarter
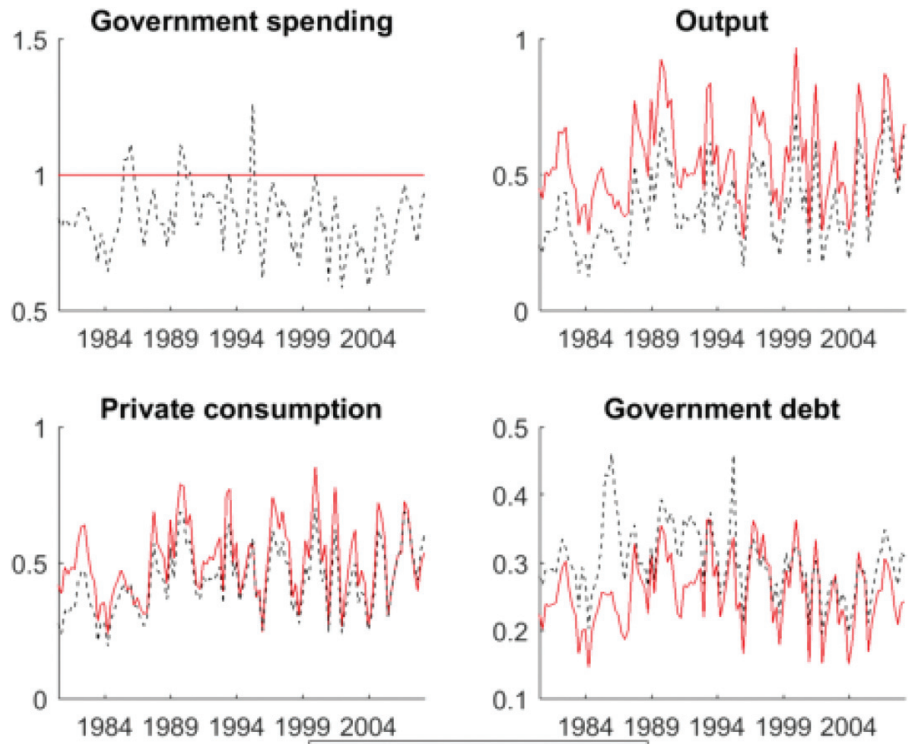

impact …… 3rd quarter 
Figure 19. Australia-IRF on Impact and in the Third Quarter
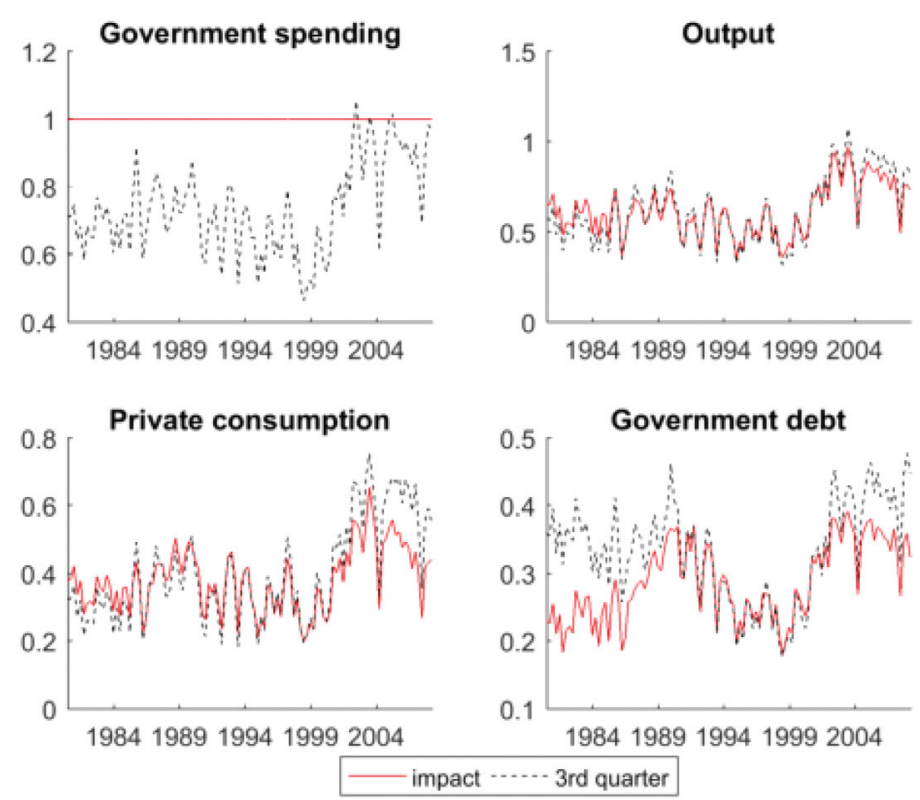

\section{Appendix 5. Illustration of the Estimated "Uncertainty"}

This appendix provides more details regarding the uncertainty of the results produced by our benchmark TVP-VAR model. Figures 20 and 21 show median and centered 68 percent of posterior distribution of IRFs on impact.

The figures demonstrate that vast majority of changes in impact over time cannot be viewed as statistically significant in the Bayesian sense. Some evidence of change can be detected only for the impact response of interest rate for the United States. 
Figure 20. Canada-IRF on Impact with Centered 68 Percent of the Posterior Distribution
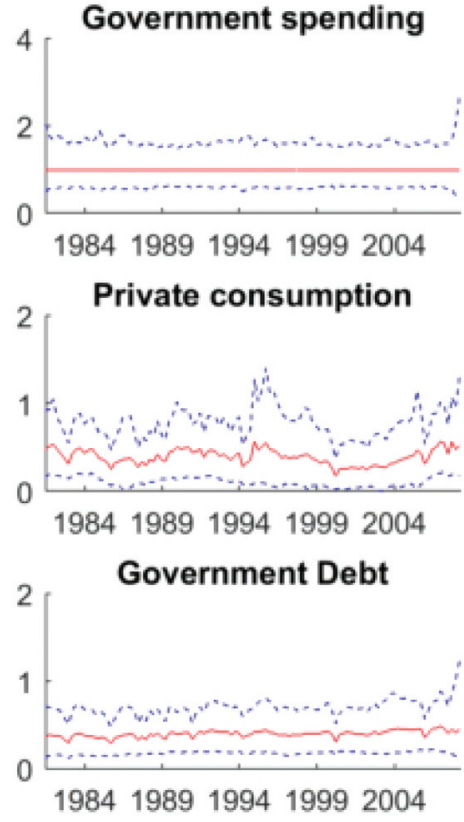

Output

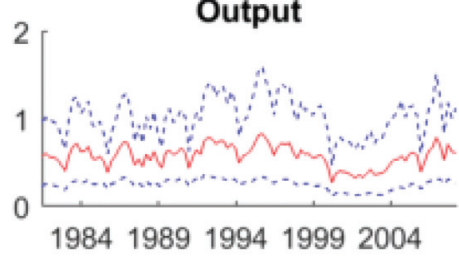

Interest rate

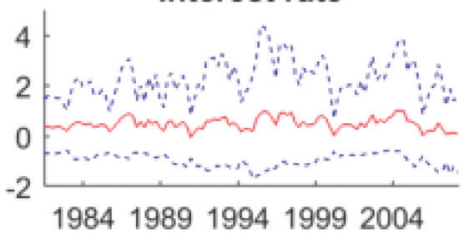

median

16th percentile

84th percentile

Figure 21. United States-IRF on Impact with Centered 68 Percent of the Posterior Distribution

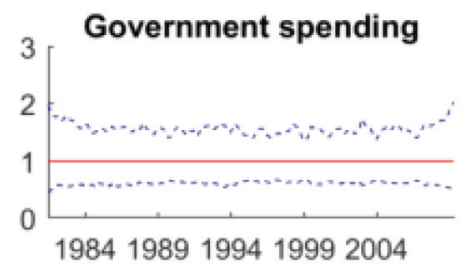

Private consumption
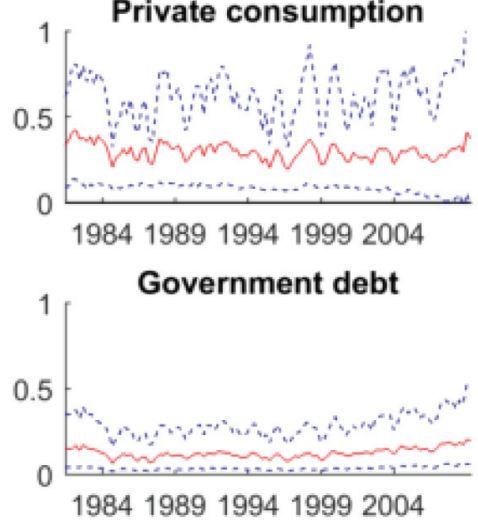

Output

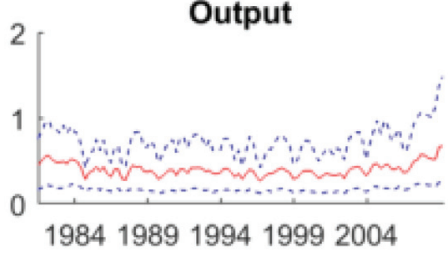

Interest rate
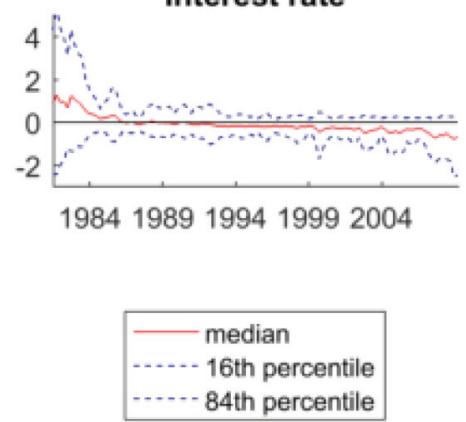


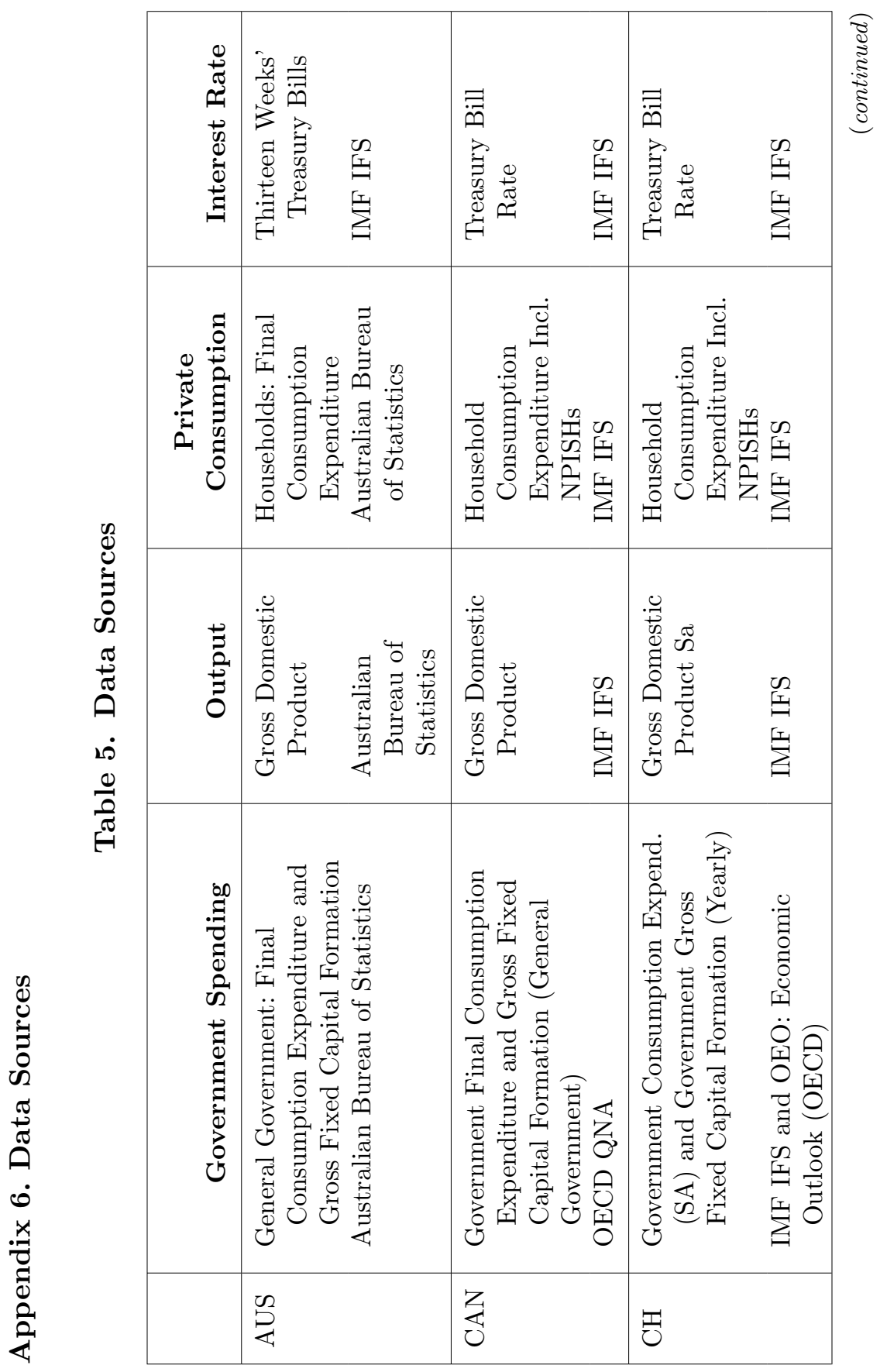




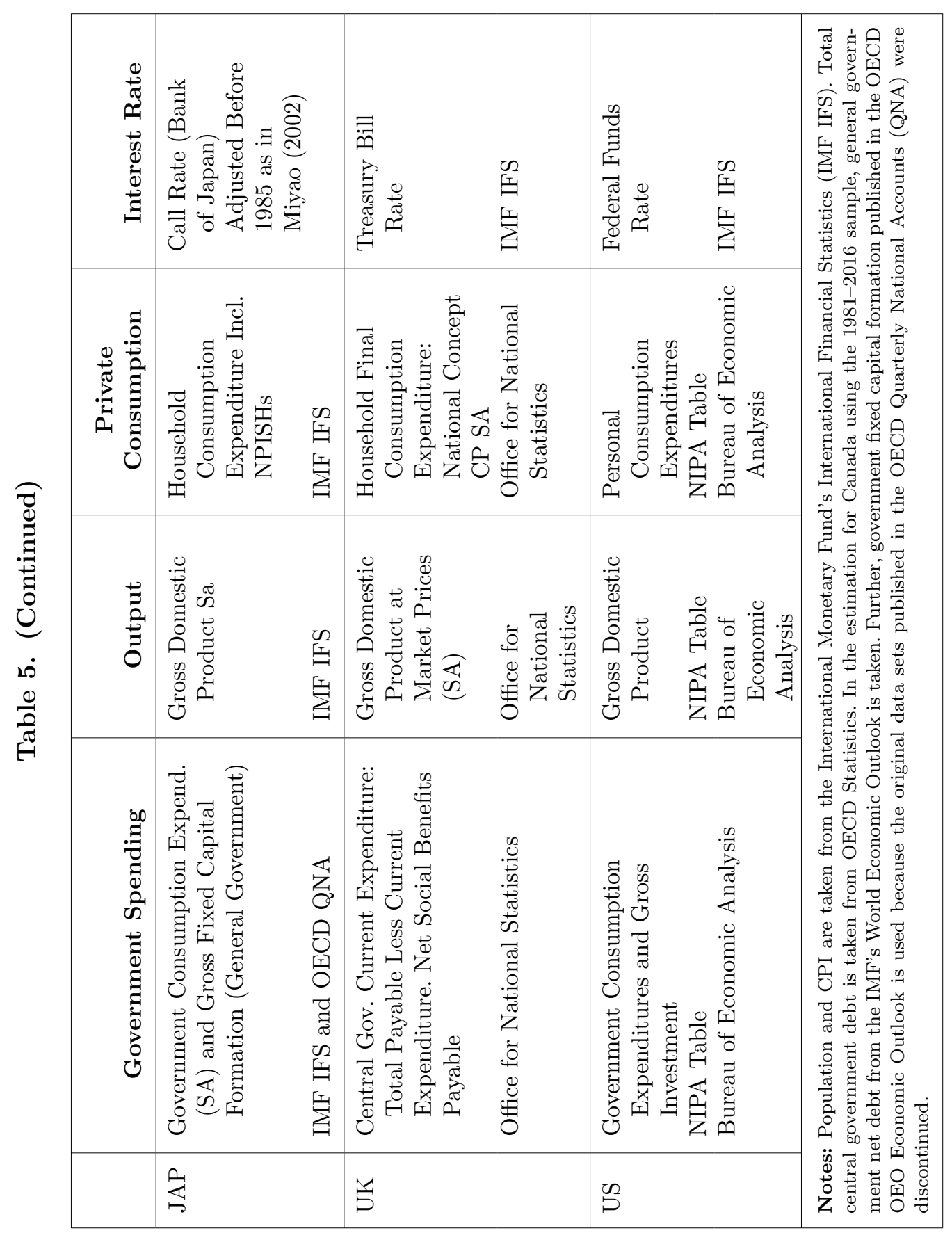




\section{References}

Abbate, A., S. Eickmeier, W. Lemke, and M. Marcellino. 2016. "The Changing International Transmission of Financial Shocks: Evidence from a Classical Time-Varying FAVAR." Journal of Money, Credit and Banking 48 (4): 573-601.

Batini, N., G. Callegari, and J. Guerreiro. 2011. "An Analysis of U.S. Fiscal and Generational Imbalances: Who Will Pay and How?" IMF Working Paper No. 11/72.

Baumeister, C., and G. Peersman. 2013. "Time-Varying Effects of Oil Supply Shocks on the US Economy." American Economic Journal: Macroeconomics 5 (4): 1-28.

Benati, L. 2008. "The 'Great Moderation' in the United Kingdom." Journal of Money, Credit and Banking 40 (11): 121-47.

Benati, L., and P. Surico. 2008. "Evolving U.S. Monetary Policy and the Decline of Inflation Predictability." Journal of the European Economic Association 6 (2-3): 634-46.

Bianchi, F., H. Mumtaz, and P. Surico. 2009. "The Great Moderation of the Term Structure of UK Interest Rates." Journal of Monetary Economics 56 (6): 856-71.

Blanchard, O. J., and R. Perotti. 2002. "An Empirical Characterization of the Dynamics Effects of Changes in Government Spending and Taxes on Output." Quarterly Journal of Economics 117 (44): 1329-68.

Brash, D. 2011a. "Monetary and Fiscal Policy: How an Agreed Inflation Target Affects Fiscal Policy." Economic Papers 30 (1): $15-17$.

. 2011b. Don Brash Interviewed by Jan Libich on MonetaryFiscal Interactions, May 26, La Trobe University, Melbourne, Australia. Available at http://youtu.be/Nq99Wm4b920.

Caldara, D., and C. Kamps. 2010. "The Analytics of the Sign Restrictions Approach to Shock Identification: A Framework for Understanding the Empirical Macro Puzzles." 2010 Meeting Paper No. 335, Society for Economic Dynamics.

Canova, F. 2007. Methods for Applied Macroeconomic Research. Princeton, NJ: Princeton University Press. 
Canova, F., L. Gambetti, and E. Pappa. 2007. "The Structural Dynamics of Output Growth and Inflation: Some International Evidence." Economic Journal 117 (519): 167-91.

Canova, F., and E. Pappa. 2007. "Price Differentials in Monetary Unions: The Role of Fiscal Shocks." Economic Journal 117 (520): $713-37$.

Canova, F., and M. Paustian. 2011. "Business Cycle Measurement with Some Theory." Journal of Monetary Economics 58 (4): $345-61$.

Carter, C. K., and R. Kohn. 1994. "On Gibbs Sampling for State Space Models." Biometrika 81 (3): 541-53.

Clarida, R., J. Galí, and M. Gertler. 1998. "Monetary Policy Rules in Practice: Some International Evidence." European Economic Review 42 (므): 1033-67.

- 2000. "Monetary Policy Rules and Macroeconomic Stability: Evidence and Some Theory." Quarterly Journal of Economics 115 (1): $147-80$.

Cobham, D. 2013. "Central Banks and House Prices in the Runup to the Crisis." Oxford Economic Papers 65 (Supplement 1): i42-i65.

Cogley, T., and T. J. Sargent. 2005. "Drift and Volatilities: Monetary Policies and Outcomes in the Post WWII U.S." Review of Economic Dynamics 8 (2): 262-302.

Davig, T., and E. M. Leeper. 2011. "Monetary-Fiscal Policy Interactions and Fiscal Stimulus." European Economic Review 55 (2): $211-27$.

Del Negro, M., and G. Primiceri. 2014. "Time-Varying Structural Vector Autoregressions and Monetary Policy: A Corrigendum." Staff Report No. 619, Federal Reserve Bank of New York.

Dotsey, M. 2006. "A Review of Inflation Targeting in Developed Countries." Business Review (Federal Reserve Bank of Philadelphia) Q3.

Dungey, M., and R. Fry. 2009. "The Identification of Fiscal and Monetary Policy in a Structural VAR." Economic Modelling 26 (6): $1147-60$.

Eickmeier, S., and B. Hofmann. 2013. "Monetary Policy, Housing Booms, and Financial (Im)Balances." Macroeconomic Dynamics 17 (04): 830-60. 
Fatás, A., and I. Mihov. 2001. "The Effects of Fiscal Policy on Consumption and Employment: Theory and Evidence." CEPR Discussion Paper No. 2760.

Fry, R., and A. R. Pagan. 2011. "Sign Restrictions in Structural Vector Autoregressions: A Critical Review." Journal of Economic Literature 49 (4): 938-60.

Galí, J., J. D. López-Salido, and J. Vallés. 2007. "Understanding the Effects of Government Spending on Consumption." Journal of the European Economic Association 5 (1): 227-70.

Herrendorf, B. 1998. "Inflation Targeting as a Way of Precommitment." Oxford Economic Papers 50 (3): 431-4.

International Monetary Fund. 2009. "Fiscal Implications of the Global Economic and Financial Crisis." IMF Staff Position Note No. 09/13.

Jacquier, E., N. G. Polson, and P. E. Rossi. 1994. "Bayesian Analysis of Stochastic Volatility Models." Journal of Business and Economic Statistics 12 (4): 371-89.

Jondeau, E., H. Le Bihan, and C. Galles. 2004. "Assessing Generalized Method-of-Moments Estimates of the Federal Reserve Reaction Function." Journal of Business and Economic Statistics 22 (2): $225-39$.

Kirchner, M., J. Cimadomo, and S. Hauptmeier. 2010. "Transmission of Government Spending Shocks in the Euro Area: Time Variation and Driving Forces." ECB Working Paper No. 1219.

Kirsanova, T., and S. le Roux. 2013. "Commitment vs. Discretion in the UK: An Empirical Investigation of the Monetary and Fiscal Policy Regime." International Journal of Central Banking 9 (4, December): 99-152.

Kleibergen, F. 2005. "Testing Parameters in GMM without Assuming That They Are Identified." Econometrica 73 (44): 1103-23.

Leeper, E. M. 1991. "Equilibria Under 'Active' and 'Passive' Monetary and Fiscal Policies." Journal of Monetary Economics 27 (11): $129-47$.

Leeper, E. M., and B. Li. 2015. "On the Bias in Estimates of Fiscal Policy Behavior." Manuscript, Indiana University.

Leeper, E. M., T. B. Walker, and S. S. Yang. 2010. "Government Investment and Fiscal Stimulus." Journal of Monetary Economics 57 (8): 1000-1012. 
LeSage, J. P. 1999. Applied Econometrics using MATLAB. University of Toledo.

Libich, J., D. T. Nguyen, and P. Stehlík. 2015. "Monetary Exit and Fiscal Spillovers." European Journal of Political Economy 40 (Part A): 184-206.

Libich, J., J. Savage, and C. E. Walsh. 2011. "Monetary-Fiscal Interactions: How to Improve Policy Outcomes?" Economic Papers 30 (11): $1-5$.

Martin, C., and C. Milas. 2010. "The Sub-Prime Crisis and UK Monetary Policy." International Journal of Central Banking 6 (3, September): 119-44.

Masson, P. R., M. A. Savastano, and S. Sharma. 1997. "The Scope for Inflation Targeting in Developing Countries." IMF Working Paper No. 97/130.

Mauro, P. 2011. Chipping Away at Public Debt: Sources of Failure and Keys to Success in Fiscal Adjustment. International Monetary Fund. Washington, DC: John Wiley \& Sons.

Mavroeidis, S. 2010. "Monetary Policy Rules and Macroeconomic Stability: Some New Evidence." American Economic Review 100 (11): 491-503.

Mertens, K., and M. O. Ravn. 2010. "Measuring the Impact of Fiscal Policy in the Face of Anticipation: A Structural VAR Approach." Economic Journal 120 (544): 393-413.

Miyao, R. 2002. "The Effects of Monetary Policy in Japan." Journal of Money, Credit and Banking 34 (2): 376-92.

Mountford, A., and H. Uhlig. 2009. "What Are the Effects of Fiscal Policy Shocks?" Journal of Applied Econometrics 24 (6) : 960-92.

Mumtaz, H., and L. Sunder-Plassmann. 2013. "Time-Varying Dynamics of the Real Exchange Rate: An Empirical Analysis." Journal of Applied Econometrics 28 (3): 495-525.

Pappa, E. 2009. "The Effects of Fiscal Shocks on Employment and the Real Wage." International Economic Review 50 (11): 217-44. . 2010. "Government Spending Multipliers: An International Comparison." Mimeo, Universitat Autonoma de Barcelona.

Paustian, M. 2007. "Assessing Sign Restrictions." B.E. Journal of Macroeconomics 7 (1): 1-33.

Pereira, M. C., and A. S. Lopes. 2010. "Time Varying Fiscal Policy in the U.S." CEMAPRE Working Paper No. 1004. 
Perotti, R. 2008. "In Search of the Transmission Mechanism of Fiscal Policy." In NBER Macroeconomics Annual 2007, Vol. 22, ed. D. Acemoglu, K. Rogoff, and M. Woodford, 169-226 (chapter 3). University of Chicago Press.

Primiceri, G. E. 2005. "Time Varying Structural Vector Autoregressions and Monetary Policy." Review of Economic Studies 72 (3): $821-52$.

Raftery, A. E., and S. Lewis. 1992. "How Many Iterations in the Gibbs Sampler?" In Bayesian Statistics 4, ed. J. M. Bernardo, J. O. Berger, A. P. Dawid, and A. F. M. Smith, 297-346. Oxford University Press.

Ramey, V. A. 2011. "Identifying Government Spending Shocks: It's All in the Timing." Quarterly Journal of Economics 126 (1): $1-50$.

2016. "Defense News Shocks, 1889-2015: Estimates Based on News Sources." Unpublished paper, University of California, San Diego. Available at http://econweb.ucsd.edu/ vramey/ research/Defense_News_Narrative.pdf.

Ramey, V. A., and M. D. Shapiro. 1998. "Costly Capital Reallocation and the Effects of Government Spending." CarnegieRochester Conference Series on Public Policy 48 (1): 145-94.

Romer, C. D., and D. H. Romer. 2004. "A New Measure of Monetary Shocks: Derivation and Implications." American Economic Review 94 (44): 1055-84.

Sargent, T. J., and N. Wallace. 1981. "Some Unpleasant Monetarist Arithmetic." Quarterly Review (Federal Reserve Bank of Minneapolis) 5 (3): $1-17$.

Sims, C. A., J. H. Stock, and M. W. Watson. 1990. "Inference in Linear Time Series Models with Some Unit Roots." Econometrica 58 (10): 113-44.

Stock, J. H., J. H. Wright, and M. Yogo. 2002. "A Survey of Weak Instrument and Weak Identification in Generalized Method of Moments." Journal of Business and Economic Statistics 20 (4): $518-29$.

Tulip, P. 2014. "Fiscal Policy and the Inflation Target." International Journal of Central Banking 10 (2, June): 63-96.

Wieland, J. F., and M. J. Yang. 2016. "Financial Dampening." NBER Working Paper No. 22141. 